\title{
The ribose methylation enzyme FTSJ1 has a conserved role in neuron morphology and learning performance
}

Dilyana G Dimitrova ${ }^{1 *}$, Mira Brazane ${ }^{1 *}$, Julien Pigeon², Chiara Paolantoni ${ }^{3}$, Tao Ye ${ }^{4}$, Virginie Marchand $^{5}$, Bruno Da Silva ${ }^{1}$, Elise Schaefer ${ }^{6}$, Margarita T Angelova ${ }^{1}$, Zornitza Stark ${ }^{7}$, Martin Delatycki $^{7}$, Tracy Dudding-Byth ${ }^{8}$, Jozef $\mathrm{Gecz}^{9}$, Pierre-Yves Placais ${ }^{10}$, Laure Teysset ${ }^{1}$, Thomas Preat ${ }^{10}$, Amélie Piton ${ }^{4}$, Bassem A. Hassan ${ }^{2}$, Jean-Yves Roignant ${ }^{3,11}$, Yuri Motorin ${ }^{12}$ and Clément Carré ${ }^{1, \# .}$

${ }^{1}$ Transgenerational Epigenetics \& small RNA Biology, Sorbonne Université, Centre National de la Recherche Scientifique, Laboratoire de Biologie du Développement - Institut de Biologie Paris Seine, 9 Quai Saint Bernard, 75005 Paris, France.

${ }^{2}$ Paris Brain Institute-Institut du Cerveau (ICM), Sorbonne Université, Inserm, CNRS, Hôpital Pitié-Salpêtrière, Paris, France.

${ }^{3}$ Center for Integrative Genomics, Génopode Building, Faculty of Biology and Medicine, University of Lausanne, Lausanne, Switzerland.

${ }^{4}$ Institute of Genetics and Molecular and Cellular Biology, Strasbourg University, CNRS UMR7104, INSERM U1258, 67400 Illkirch, France.

${ }^{5}$ Université de Lorraine, CNRS, INSERM, EpiRNASeq Core Facility, UMS2008/US40 IBSLor ,F-54000 Nancy, France.

${ }^{6}$ Service de Génétique Médicale, Hôpitaux Universitaires de Strasbourg, Institut de Génétique Médicale d’Alsace, Strasbourg, France.

${ }^{7}$ Victorian Clinical Genetics Services, Murdoch Children's Research Institute, Melbourne, VIC, Australia. Department of Paediatrics, The University of Melbourne, Melbourne, VIC, Australia.

${ }^{8}$ University of Newcastle, Newcastle, NSW Australia.

${ }^{9}$ Adelaide Medical School and Robinson Research Institute, The University of Adelaide; South Australian Health and Medical Research Institute, Adelaide, South Australia, 5000, Australia.

${ }^{10}$ Energy \& Memory, Brain Plasticity Unit, CNRS, ESPCI Paris, PSL Research University, Paris, France.

${ }^{11}$ Institute of Pharmaceutical and Biomedical Sciences, Johannes Gutenberg-University Mainz, Staudingerweg 5, 55128 Mainz, Germany.

${ }^{12}$ Université de Lorraine, CNRS, UMR7365 IMoPA, F-54000 Nancy, France.

"Contributed equally to this work. "Correspondence: clement.carre@.gmail.com; clement.carre@sorbonne-universite.fr

\section{ABSTRACT}

FTSJ1 is a conserved human 2'-O-methyltransferase (Nm-MTase) that modifies several transfer RNAs (tRNAs) at position 32 and the wobble position 34 in the AntiCodon Loop (ACL). Its loss of function has been linked to Non-Syndromic X-Linked Intellectual Disability (NSXLID), and more recently to cancers. However, the molecular mechanisms underlying these pathologies are currently unclear. Here we report a novel FTSJ1 pathogenic variant from a NSXLID patient. Using blood cells derived from this patient and other affected individuals carrying FTSJ1 mutations, we performed an unbiased and comprehensive RiboMethSeq analysis to map the ribose methylation $(\mathrm{Nm})$ on all tRNAs and identify novel targets. In addition, we performed a transcriptome analysis in these cells and found that several genes previously associated with intellectual disability and cancers were deregulated. We also found changes in the miRNA population that suggest potential cross-regulation of some miRNAs with these key mRNA targets. Finally, we show that differentiation of FTSJ1-depleted human neuronal progenitor cells (NPC) into neurons displays long and thin spine neurites compared to control cells. These defects are also observed in Drosophila and are associated with long term memory deficit in this organism. Altogether, our study adds insight into FTSJ1 pathologies in human by the identification of novel FTSJ1 targets and the defect in neuron morphology. 


\section{INTRODUCTION}

RNA modifications represent a novel layer of post-transcriptional gene regulation ${ }^{1-3}$. Due to their variety and dynamic nature, they rapidly adapt gene expression programs in response to developmental changes or environmental variations. One of the most abundant RNA modifications is 2'-O-methylation (ribose methylation, $\mathrm{Nm}$ ). $\mathrm{Nm}$ can affect the properties of RNA molecules in multiple ways e.g. stability, interactions and functions ${ }^{4-6}$. Nm residues are abundant in ribosomal RNAs (rRNAs) and transfer RNAs (tRNAs) ${ }^{7,8}$, but are also found in other RNA types such as small nuclear RNAs (snRNAs) 9,10, small non-coding RNAs (sncRNAs) ${ }^{5,11-14}$ and messenger RNAs (mRNAs) ${ }^{9,10,15}$. Many Nm positions are conserved through evolution and their presence is essential for maintaining healthy physiological functions. The loss of certain $\mathrm{Nm}$ modifications and/or Nm-modifying enzymes has been associated to various pathological conditions (reviewed in ${ }^{16}$ ), including cancers ${ }^{17-20}$ and brain diseases ${ }^{21-24}$.

FTSJ1 is a human tRNA 2'-O-methyltransferase (Nm-MTase), which belongs to the large phylogenetically conserved superfamily of Rrmj/fibrillarin RNA methyltransferases ${ }^{25,26}$. Human males individuals bearing a hemizygous loss of function variant in the FTSJ1 gene suffer from significant limitations both in intellectual functioning and in adaptive behavior. Similar phenotypes, including impaired learning and memory capacity, were recently observed in Ftsj1 $\mathrm{KO}$ mice that also present a reduced body weight and bone mass, as well as altered energy metabolism ${ }^{27}$. In flies, we recently showed that the loss of the two FTSJ1 homologs (i.e Trm7_32 and Trm7_34) provokes reduced lifespan and body weight, and affects RNAi antiviral defences and locomotion ${ }^{28}$. Finally, Ftsj1 mutants in yeast ( $\Delta$ trm7) grow poorly due to a constitutive general amino acid control (GAAC) activation and the possible reduced availability of aminoacylated RRNA $^{\text {Phe }}$ 29-31. Interestingly, this growth phenotype can be rescued by human FTSJ1, indicating a conserved evolutionary function.

Most of the knowledge on FTSJ1's molecular functions are derived from yeast studies. Trm7 in Saccharomyces cerevisiae methylates positions 32 and 34 in the AntiCodon Loop (ACL) of specific tRNA targets: tRNA ${ }^{\text {Phe(GAA) }}$ tRNA ${ }^{\operatorname{Trp}(C C A)}$ and $\operatorname{tRN} A^{\operatorname{Leu}(\mathrm{UAA})}{ }^{29,30}$. To achieve 2'-O-methylation, Trm7 teams up with two other proteins: Trm732 for the methylation of cytosine at position 32, and with Trm734 for the methylation of cytosine or guanine at position $34{ }^{30,32}$. The presence of both $\mathrm{Cm}_{32}$ and $\mathrm{Gm}_{34}$ in tRNA ${ }^{\text {Phe(GAA) }}$ is required for efficient conversion of $\mathrm{m}^{1} \mathrm{G}_{37}$ to wybutosine $\left(\mathrm{yW}_{37}\right)$ by other proteins. This molecular circuitry is conserved in the phylogenetically distinct Schizosaccharomyces pombe and humans ${ }^{23,32-34}$. In Drosophila, we found that Trm7_32 and Trm7_34 modify, respectively, positions 32 and 34 in the ACL on tRNA ${ }^{\text {Phe(GAA) }}, \operatorname{tRNA}^{\operatorname{Trp}(\mathrm{CCA})}$ and tRNA ${ }^{\text {Leu(CAA) } 28}$. In this organism, we also identified novel tRNA targets for these two enzymes (tRNA ${ }^{\text {Gln(CUG) }}$ and $t R N A^{\text {Glu(CUC) }}$ ), which raised the 
question about their conservation in humans. A recent publication reported that human

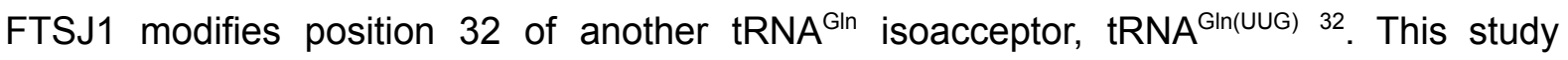
performed in HEK293T cells tested a selected subset of tRNAs using tRNA purification followed by MS analysis. It was shown that position 32 of tRNA ${ }^{\operatorname{Arg}(U C G)}$, $\operatorname{tRNA}{ }^{\operatorname{Arg}(C C G)}$ and tRNA $^{\text {Arg(ACG) }}$ as well as position 34 on tRNA $^{\text {Arg(CCG) }}$ and tRNA ${ }^{\text {Leu(CAG) }}$ are also 2'-O-methylated by human FTSJ1. tRNA ${ }^{\mathrm{Arg}(\mathrm{ACG})}$ was originally identified as a target of fly Trm7_32 ${ }^{28}$, while human tRNA ${ }^{\text {Leu(CAA) } 35}$ and yeast tRNA ${ }^{\text {Leu(UAA) } 30}$ were predicted targets of FTSJ1 and Trm7, respectively. However, a comprehensive and unbiased analysis of all possible FTSJ1 tRNA targets was not performed, particularly in human patient samples, leaving the full spectrum of FTSJ1 tRNA substrates yet to be identified.

Previously, the enzymatic activity of FTSJ1 on selected tRNAs has been revealed through HPLC (High-Performance Liquid Chromatography) ${ }^{23}$ and more recently through UPLC-MS/MS (Ultra-Performance Liquid Chromatography-Mass Spectrometry/Mass Spectrometry) ${ }^{32}$. Both approaches analyse mononucleotides derived from selected tRNAs and are based on already reported sequences. The exact position of the modified nucleotide was thus inferred from available information on tRNA sequences and modification profiles database ${ }^{36,37}$. Recently, a new method called RiboMethSeq was established and allows the identification of $\mathrm{Nm}$ sites in a complete unbiased manner, based on the protection conferred by the ribose methylation to alkaline digestion ${ }^{8,38}$. This offers the possibility to identify every $\mathrm{Nm}$ site regulated by a particular enzyme, especially when investigating abundant RNA, such as tRNA.

In this study we took advantage of this novel approach to identify the full set of FTSJ1's tRNA targets in human. We report a novel FTSJ1 pathogenic variant from a NSXLID patient. Using blood cells derived from this affected individual and other individuals carrying distinct FTSJ1 mutations, we performed an unbiased and comprehensive RiboMethSeq analysis to map the ribose methylation on all tRNAs and reveal new targets. In addition, we performed a transcriptome analysis in these FTSJ1 depleted cells and found that several genes previously associated with intellectual disability (ID) and cancers were deregulated. We also found changes in the miRNA population that suggest potential cross-regulation of some miRNAs with these key mRNA targets. Finally, in accordance with the known importance of FTSJ1 during brain development in mice and its involvement in intellectual disability in humans, we showed that human Neuronal Progenitor Cells (NPC) with inactivated FTSJ1 present abnormal neurite morphology. We also observed this phenotype in Drosophila as well as a specific deficit in long term memory. Altogether, our study reveals new targets potentially involved in FTSJ1 pathologies in human and demonstrates a conserved function in neuron morphology and function. 


\section{MATERIALS \& METHODS}

\section{FTSJ1 variants and lymphoblastoid cell lines (LCLs)}

The various lymphoblastoid cell lines (LCLs) were generated using established methods from blood samples of NSXLID affected or healthy male individuals. The cells were cultured in RPMI-1640 medium with L-glutamine and sodium bicarbonate (ref. R8758-500ML, SIGMA) supplemented with $10 \%$ FBS (Gibco) and $1 \%$ penicillin-streptomycin (ref. P0781, SIGMA) at $37^{\circ} \mathrm{C}$ with $5 \% \mathrm{CO}_{2}$. Cells were split at $1 / 2$ dilution approximately $24 \mathrm{~h}$ before being collected for RNA extraction with TRI-Reagent (Sigma Aldrich) following the manufacturer's instructions.

6514AW \& 6514JW (LCL65AW \& LCL65JW in this study): Family A3 - LCLs from two brothers with mild or severe ID associated with psychiatric manifestations (anger, aggression, anxiety, depression, schizophrenia requiring medication) bearing a splice variant in FTSJ1: c. $121+1$ delG ${ }^{39}$. This variant leads to a retention of intron 2, creating a premature stop codon (p.Gly41Valfs*10). Part of the transcripts undergo nonsense-mediated mRNA decay.

11716IJ (LCL11 in this study): Family A18 - LCL from one male with moderate to severe mental retardation without dysmorphic features carrying an interstitial microdeletion at Xp11.23. The extent of the deletion was subsequently delineated to about $50 \mathrm{~kb}$ by regular PCR and included only the SLC38A5 and FTSJ1 genes. qPCR with the FTSJ1-ex3 primers is negative, thus demonstrating the complete deletion of FTSJ1 locus ${ }^{40}$.

22341SR (LCL22 in this study): Family 7 (A26P) - LCL from one male with moderate ID and psychiatric features (mild anxiety and compulsive behavior) carrying a missense mutation c.76G>C; p.Ala26Pro in FTSJ1. This family has been reported previously ${ }^{23}$.

LCL-MM: This is a newly reported family. The LCL has been generated from one male with mild ID and behavioral problems carrying a hemizygous variant c.362-2A>T in FTSJ1. The mutation is predicted to disrupt the acceptor splice site of exon 6 (NM_012280.3: c.362-2A>T). This variant causes a skipping of the entire exon 6 in the mRNA (r.362_414del) leading to a frameshift and a premature stop codon (p.Val121Glyfs*51) (Figure S1A). Part of the transcripts undergo nonsense-mediated mRNA decay (Figure S1C). Consequently, a strong decrease of the corresponding mRNA steady state level is observed (Figure S1B). This variant was deposited in the ClinVar database (VCV000981372.1). 
18451PK (LCL18 in this study), 16806JD (LCL16 in this study), 3-2591 (LCL25 in this study) and $\underline{3-5456}$ (LCL54 in this study): LCL established from control males. Four LCLs not mutated in the FTSJ1 gene from unaffected males of similar age were used as controls.

\section{LCL MM variant characterization at the mRNA level}

As the FTSJ1 mRNA was highly downregulated in LCL MM, characterization of the FTSJ1 transcript for this experiment was performed on total RNAs from cells treated with cycloheximide (see NMD inhibition protocol below). This allowed a three fold increase in FTSJ1 mRNA in LCL MM (Figure S1B). $1 \mu \mathrm{g}$ of total RNAs from wild type LCL 25 and LCL MM were treated with DNAse I (M0303S-NEB), and reverse transcription was carried out with random hexamer primers (S0142-Thermo Scientific ${ }^{\mathrm{TM}}$ ) using SuperScript ${ }^{\mathrm{TM}}$ III Reverse Transcriptase (18080-044- Invitrogen), following the supplier's protocol. FTSJ1 cDNAs were amplified from $2 \mu \mathrm{L}$ of $\mathrm{RT}$ reaction using the following PCR primers: (Forward: 5'-GGCAGTTGACCTGTGTGCAGC-3'; Reverse: 5'-CCCTCTAGGTCCAGTGGGTAAC-3'. $P C R$ products were sequenced using the sanger method with a forward primer hybridizing in exon 5: 5'-CCACTGCCAAGGAGATCA-3' (Figure S1A). Sequences are available upon request. Briefly, this variant causes a skipping of the entire exon 6 in the mRNA leading to a frameshift and a premature stop codon, thus undergoing nonsense-mediated mRNA decay as shown in Figure S1C. Consequently, a strong decrease of the corresponding mRNA steady state level is observed (Figure S1B). This MM variant was deposited in the ClinVar database (VCV000981372.1).

\section{RiboMethSeq}

RiboMethSeq analysis of human LCL tRNAs was performed as described in ${ }^{8}$. Briefly, tRNAs extracted from LCLs were fragmented in $50 \mathrm{mM}$ bicarbonate buffer $\mathrm{pH} 9.2$ for 15 minutes at $95^{\circ} \mathrm{C}$. The reaction was stopped by ethanol precipitation. The pellet was washed with $80 \%$ ethanol and sizes of generated RNA fragments were assessed by capillary electrophoresis using a small RNA chip on Bioanalyzer 2100 (Agilent, USA). RNA fragments were directly 3'-end dephosphorylated using $5 \mathrm{U}$ of Antarctic Phosphatase (New England Biolabs, UK) for 30 minutes at $37^{\circ} \mathrm{C}$. After inactivation of the phosphatase for 5 minutes at $70^{\circ} \mathrm{C}$, RNA fragments were phosphorylated at the $5^{\prime}$-end using T4 PNK and $1 \mathrm{mM}$ ATP for one hour at $37^{\circ} \mathrm{C}$. End-repaired RNA fragments were then purified using RNeasy MinElute Cleanup kit (QIAGEN, Germany) according to the manufacturer's recommendations. RNA fragments were converted to library using NEBNext ${ }^{\circledR}$ Small RNA Library kit (ref\#E7330S, New England Biolabs, UK) following the manufacturer's instructions. DNA library quality was assessed using a High Sensitivity DNA chip on a Bioanalyzer 2100. Library sequencing was 
performed on Illumina HiSeq 1000 in single-read mode for $50 \mathrm{nt}$. Primary analysis of sequencing quality was performed with RTA 2.12 software, to insure $>$ Q30 quality score for $>95 \%$ of obtained sequences.

Following SR50 sequencing run, demultiplexing was performed with BclToFastq v2.4, reads not passing quality filter were removed. Raw reads after demultiplexing were trimmed with Trimmomatic v0.32 ${ }^{41}$. Alignment to the reference tDNA sequences was performed with bowtie 2 ver2.2.4 ${ }^{42}$ in End-to-End mode. Uniquely mapped reads were extracted from *.sam file by RNA ID and converted to *.bed format using bedtools v2.25.0 ${ }^{43}$. Positional counting of 5'-and 3'-ends of each read was performed with awk Unix command. Further treatment steps were performed in $\mathrm{R}$ environment (v3.0.1). In brief, 5'-and 3'-end counts were merged together by RNA position and used for calculation of ScoreMEAN (derived from MAX Score ${ }^{44}$, as well as Scores $A$ and $B{ }^{45}$ and MethScore (Score C) ${ }^{38}$. Scores were calculated for two neighboring nucleotides. Profiles of RNA cleavage at selected (candidate and previously known) positions were extracted and visually inspected.

\section{mRNA sequencing and data analysis}

mRNA sequencing was performed as in ${ }^{46} .5 \mu \mathrm{g}$ of total RNA were treated by $1 \mathrm{MBU}$ of DNAse (BaseLine-Zero ${ }^{\mathrm{TM}}$ DNAse, Epicentre, USA) for $20 \mathrm{~min}$ at $37^{\circ} \mathrm{C}$ to remove residual genomic DNA contamination. RNA quality was verified by PicoRNA chip on Bioanalyzer 2100 (Agilent, USA) to ensure RIN (RNA Integrity Number) > 8.0. PolyA + fraction was isolated from $4.5 \mu \mathrm{g}$ of DNAse-treated total RNA using NEBNext Oligo $\mathrm{d}(\mathrm{T}) 25$ Magnetic beads kit (NEB, USA), according to manufacturer's recommendations. PolyA + enrichment and the absence of residual rRNA contamination were verified using PicoRNA chips on Bioanalyzer 2100 (Agilent, USA). PolyA + fraction (1 ng for each sample) was used for whole-transcriptome library preparation using ScriptSeq v2 RNA-Seq kit (Illumina, USA). Libraries amplified in 14 PCR cycles were purified using Agencourt AMPure XP beads (Beckman-Coulter, USA), at a ratio $0.9 x$ to remove adapter dimer contamination. Quality of the libraries was verified by HS DNA Chip on Bioanalyzer 2100 (Agilent, USA) and quantification done by Qubit 2.0 with appropriate RNA quantification kit. Sequencing was performed on HiSeq1000 (Illumina, USA) in single read SR50 mode. About 50 million of raw sequencing reads were obtained for each sample. Adapters were trimmed by Trimmomatic v0.32 ${ }^{41}$ and the resulting sequencing reads aligned in sensitive-local mode by Bowtie 2 v2.2.4 ${ }^{47}$ to hg19 build of human genome. Differential expression was analyzed using *.bam files in DESeq2 package ${ }^{48}$ under R environment. Analysis of KEGG and Gene Ontology pathways for differentially expressed genes was done under $\mathrm{R}$ environment. 


\section{small RNA sequencing and data analysis}

Small RNA-Seq libraries were generated from 1000 ng of total RNA using TruSeq Small RNA Library Prep Kit (Illumina, San Diego, CA), according to manufacturer's instructions. Briefly, in the first step, RNA adapters were sequentially ligated to each end of the RNA, first the 3' RNA adapter that is specifically modified to target microRNAs and other small RNAs, then the 5' RNA adapter. Small RNA ligated with 3' and 5' adapters were reverse transcribed and $\mathrm{PCR}$ amplified $\left(30 \mathrm{sec}\right.$ at $98^{\circ} \mathrm{C}$; $\left[10 \mathrm{sec}\right.$ at $98^{\circ} \mathrm{C}, 30 \mathrm{sec}$ at $60^{\circ} \mathrm{C}, 15$ sec at $72^{\circ} \mathrm{C}$ ] $\times 13$ cycles; $10 \mathrm{~min}$ at $72^{\circ} \mathrm{C}$ ) to create cDNA constructs. Amplified cDNA constructs of 20 to $40 \mathrm{nt}$ were selectively isolated by acrylamide gel purification followed by ethanol precipitation. The final cDNA libraries were checked for quality and quantified using capillary electrophoresis and sequenced on the Illumina HiSeq 4000 at the Institut de Génétique et de Biologie Moléculaire et Cellulaire (IGBMC) GenomEast sequencing platform.

For small RNA data analysis, adapters were trimmed from total reads using FASTX_Toolkit [http://hannonlab.cshl.edu/fastx toolkit/]. Only trimmed reads with a length between 15 and 40 nucleotides were kept for further analysis.

Data analysis was performed according to published pipeline ncPRO-seq [https://www.ncbi.nlm.nih.gov/pubmed/23044543]. Briefly, reads were mapped onto the human genome assembly hg19 with Bowtie v1.0.0. The annotations for miRNAs were done with miRBase v21. The normalization and comparisons of interest were performed using the test for differential expression, proposed by ${ }^{48}$ and implemented in the Bioconductor package DESeq2 v1.22.2 [ $\underline{\mathrm{http}}$ ://bioconductor.org/]. MicroRNA target prediction was performed using miRNet 2.0 [https://www.mirnet.ca/miRNet/home.xhtml]

\section{Northern blotting}

For northern blotting analysis of tRNA, $5 \mu \mathrm{g}$ of total RNA from human LCLs were resolved on $15 \%$ urea-polyacrylamide gels for approximately $2 \mathrm{~h}$ in $0.5 \mathrm{x}$ TBE buffer at $150 \mathrm{~V}$, then transferred to Hybond-NX membrane (GE Healthcare) in 0,5x TBE buffer for $1 \mathrm{~h}$ at 350 $\mathrm{mA}$ of current and EDC-cross-linked for $45 \mathrm{~min}$ at $60^{\circ} \mathrm{C}$ with a solution containing $33 \mathrm{mg} / \mathrm{ml}$ of 1-ethyl-3-(3-dimethylaminopropyl)carbodiimide (EDC) (Sigma Aldrich), $11 \mathrm{ng} / \mathrm{ul}$ of 1-methylimidazol and $0.46 \%$ of $\mathrm{HCl}$. The membranes were first pre-hybridized for $1 \mathrm{~h}$ at $42^{\circ} \mathrm{C}$ in a hybridization buffer containing $5 x \mathrm{SSC}, 7 \% \mathrm{SDS}, 5.6 \mathrm{mM} \mathrm{NaH} \mathrm{PO}_{4}, 14.4 \mathrm{mM} \mathrm{Na}_{2} \mathrm{HPO}_{4}$ and $1 \mathrm{x}$ Denhardt's solution. DNA oligonucleotide probes were labelled with ${ }^{32} \mathrm{P}$ at the 5 '-end by T4 polynucleotide kinase following manufacturer's instructions (Fermentas). The membranes were hybridized with the labelled probes overnight at $42^{\circ} \mathrm{C}$ in the hybridization buffer, then washed twice for 15 min in wash buffer A (3x SSC and 5\% SDS) and twice in 
wash buffer B (1x SSC and $1 \%$ SDS) before film exposure at $-80^{\circ} \mathrm{C}$ for variable time durations. Probe sequences are available in the Primers and Probes section.

\section{RT-qPCR}

RNA was extracted from human LCLs using TRI-Reagent (Sigma Aldrich). After DNase digestion of total RNA using the TURBO DNA-free ${ }^{\text {TM }}$ Kit (Ambion), $1 \mu \mathrm{g}$ was used in a reverse transcription reaction with Random Primers (Promega) and RevertAid Reverse Transcriptase (ref. EP0442, Thermofisher). The cDNA was used to perform qPCR on a CFX96 Touch $^{\mathrm{TM}}$ Real-Time PCR Detection System (Bio Rad) using target-specific primers. hGAPDH was used for normalization (Primers and Probes section). The analysis was performed using $\Delta \Delta \mathrm{Ct}$, on three biological replicates. Statistical analysis using a bilateral Student's t-test was performed and $p$-values were calculated.

\section{NMD inhibition test}

LCLs were seeded in $25 \mathrm{~cm}$ cell culture plates at a density of $3.10^{6}$ cells and treated with $100 \mu \mathrm{g} / \mathrm{mL}$ of cycloheximide or equal volume of water as a control for six hours. Cells were harvested by centrifugation at $1000 \mathrm{rpm}$ for $5 \mathrm{~min}$ and flash frozen in liquid nitrogen. RNA extraction was carried out using TRI-reagent (Sigma Aldrich) following the supplier's protocol. DNAse I digestion was carried out using RNAse free DNase I (M0303S- NEB), and reverse transcription on $1 \mu \mathrm{g}$ of DNase treated total RNA was performed using RevertAid Reverse Transcriptase. Quantitative PCR was performed as specified above using specific primers for FTSJ1 and GAPDH.

\section{Primers and Probes}

Northern blot analysis was performed using hsa-miR-181a-5p specific probes with the following sequences: 5'-AACATTCAACGCTGTCGGTGAGT-3' (sense probe) and 5'-ACTCACCGACAGCGTTGAATGTT-3' (antisense probe). Human U6 specific probe was used for detecting U6 as a loading control: 5'-GCAAGGATGACACGCAAATTCGTGA-3' (sense probe) and 5'-TCACGAATTTGCGTGTCATCCTTGC-3' (antisense probe).

qPCR analysis (after an RT reaction performed with random primers) were performed with the use of primers with the following sequences:

\begin{tabular}{|l|l|l|}
\hline Target Gene & Primer & Sequence \\
\hline \multirow{3}{*}{ BTBD3 } & Forward & 5'-TGGCAGATGTACATTTTGTGG-3' \\
\cline { 2 - 3 } & Reverse & 5'-AACACAGAGCTCCCAACAGC-3' \\
\hline
\end{tabular}




\begin{tabular}{|l|l|l|}
\hline \multirow{3}{*}{ SPARC } & Forward & 5'-GAGAAGGTGTGCAGCAATGA-3' \\
\cline { 2 - 3 } & Reverse & 5'-AAGTGGCAGGAAGAGTCGAA-3' \\
\hline \multirow{3}{*}{ GAPDH } & Forward & 5'-CAACGGATTTGGTCGTATTGG-3' \\
\cline { 2 - 3 } & Reverse & 5'-GCAACAATATCCACTTTACCAGAGTTAA-3' \\
\hline \multirow{3}{*}{ FTSJ1 } & Forward & 5'-CCATTCTTACGACCCAGATTTCA-3' \\
\cline { 2 - 3 } & Reverse & 5'-CCCTCTAGGTCCAGTGGGTAAC-3' \\
\hline \multirow{2}{*}{ ZNF711 } & Forward & 5'-CACACGCCAGACTCTAGAATGG-3' \\
\cline { 2 - 3 } & Reverse & 5'-CCATTCCAGCCACAAAATCTTG-3' \\
\hline
\end{tabular}

\section{iPSC culture and maintenance}

iPSCs cell line WTSli002 purchased from EBISC (European bank for induced pluripotent cells) were maintained on feeder-free conditions on Geltrex LDEV-Free hESC-qualified Reduced Growth Factor Basement Membrane Matrix (ThermoFisher Scientific, A1413302) in Essential $8^{\text {TM }}$ Flex Media Kit (ThermoFisher Scientific, A2858501) with 0,1\% Penicillin/Streptomycin (ThermoFisher Scientific, 15140122).

\section{iPSC differentiation in dorsal NPCs}

To obtain Neural progenitor cells (NPCs) from the dorsal telencephalon, embryoid bodies (EB) were formed by incubating iPSCs clusters with Accutase (ThermoFisher Scientific, A1110501) for $7 \mathrm{~min}$ at $37^{\circ} \mathrm{C}$ and dissociated into single cells. To obtain EB of the same size, $3 \times 10^{6}$ cells were added per well in the AggreWell 800 plate (STEMCELL Technologies, 34815) with Essential $8^{\mathrm{TM}}$ Flex Media supplemented with Stemgent hES Cell Cloning \& Recovery Supplement (1X, Ozyme, STE01-0014-500) and incubated at $37^{\circ} \mathrm{C}$ with $5 \% \mathrm{CO}_{2}$ (Day-1). After 24 hours in culture (Day0), EB from each microwell were collected by pipetting up and down the medium several times and transferred into Corning ${ }^{\circledR}$ non-treated culture dishes (Merck, CLS430591-500EA) in EB medium containing DMEM/F12 GlutaMAX (ThermoFisher Scientific, 35050061), 20\% KnockOut ${ }^{\text {TM }}$ Serum Replacement (ThermoFisher Scientific, 10828028), 1\% Non-Essential Amino Acid (ThermoFisher Scientific,11140035), $0,1 \%$ Penicillin/Streptomycin (ThermoFisher Scientific, 15140122), $100 \mu \mathrm{M}$ 2-mercaptoethanol (ThermoFisher Scientific, 31350010), supplemented with two inhibitors of the SMAD signalling pathway, 2,5 $\mu \mathrm{M}$ Dorsomorphin (Sigma-Aldrich, P5499) and $10 \mu \mathrm{M}$ SB-431542 (Abcam, ab120163). EB medium supplemented as described previously was changed every day for 5 days. On Day 6, floating EBs are plated on 0,01\% Poly-L-ornithine 
(Sigma-Aldrich, P4957) and $5 \mu \mathrm{g} / \mathrm{mL}$ Laminin (Sigma-Aldrich, L2020) coated dishes for rosette expansion in Neurobasal minus vitamin A (ThermoFisher Scientific 10888), B-27 supplement without vitamin A (ThermoFisher Scientific 12587), 1\% GlutaMAX (ThermoFisher Scientific 35050061), 0,1\% Penicillin/Streptomycin (ThermoFisher Scientific 15140122) and $100 \mu \mathrm{M}$ 2-Mercaptoethanol (ThermoFisher Scientific 31350010). The neural medium was supplemented with $10 \mathrm{ng} / \mathrm{mL}$ epidermal growth factor (PreproTech AF-100-15) and $10 \mathrm{ng} / \mathrm{mL}$ basic fibroblast growth factor (R\&D Systems 234-FSE-025). From day 6 to day 10 the medium was changed everyday until the appearance of rosettes. On day 10, rosettes are manually picked up using a syringe and dissociated with Accutase, then seeded on Poly-L-ornithine/Laminin coated dishes for expansion of dorsal NPCs. They were maintained with passage for two additional weeks to achieve a large pool of neural precursor cells (NPCs).

\section{NPC drug treatment}

NPCs are seeded in Poly-L-Ornithine and Laminin coated coverslips in 24 well plates at a density of $2.10^{5}$ cells per well. After 48 hours, the medium is changed and combined with $100 \mu \mathrm{M}$ of 2,6 Diaminopurine (DAP) (Sigma Aldrich 247847) or equal volume of sterile $\mathrm{H}_{2} \mathrm{O}$.

\section{NPC immunostainings}

24 hours after DAP treatment NPCs were fixed in $4 \%$ paraformaldehyde for 10 min, permeabilized and blocked for 45 minutes with blocking buffer (PBS supplemented with $0.3 \%$ Triton-X100, 2\% horse serum). Primary antibodies, Sox2 (1/500, Milipore AB5603) and DCX (1/2000, Milipore AB2253), were incubated overnight at $4^{\circ} \mathrm{C}$ using the same solution. Cells were rinsed three times with PBS and incubated 1 hour at RT with secondary antibodies and DAPI (1/10000, Sigma-Aldrich D9564) diluted in the same solution and rinsed 3 times with PBS before mounting on slides with VectaShield® Vibrance mounting medium.

\section{Neuronal cells image acquisitions}

Images were acquired in z-stacks using a confocal microscope Nikon A1R HD25 with a 60X objective. Images were flattened with a max intensity Z-projection.

\section{Neurogenesis quantification}

All cells (DAPI) from each acquisition were numbered using Fiji's point tool. Cells expressing DCX (immature neurons) and SOX2 (NPCs and intermediates which also started expressing DCX) were also numbered on 5 to 6 microscopy images. Over 1400 cells were numbered for each condition in triplicate. A ratio of DCX expressing cells is calculated over the total cell 
number and expressed in fold change and compared between DAP treated and untreated cells.

\section{Branching quantifications}

All DCX expressing neurons were traced using Simple Neurite Tracer (SNT) from the Neuroanatomy Plugin by Fiji. Length measurements of traces were performed using the SNT Measure Menu, and thin projections were counted manually using Fiji's point tool. Quantifications were performed on 5 acquisitions and each IF experiment was done in triplicate. Ratios for the number of thin projections/neuron length $(\mathrm{mm})$ were calculated and compared between DAP treated and control cells.

\section{Drosophila NMJ analysis}

For NMJ staining, third instar larvae were dissected in cold PBS and fixed with 4\% paraformaldehyde in PBS for 45 min. Larvae were then washed in PBS-T (PBS $+0.5 \%$ Triton $\mathrm{X}$-100) six times for $30 \mathrm{~min}$ and incubated overnight at $4^{\circ} \mathrm{C}$ with mouse anti-synaptotagmin, 1:200 (3H2 2D7, Developmental Studies Hybridoma Bank, DSHB). After six 30-min washes with PBS-T, secondary antibody anti-mouse conjugated to Alexa-488 and TRITC-conjugated anti-HRP (Jackson ImmunoResearch) were used at a concentration of 1:1,000 and incubated at room temperature for $2 \mathrm{~h}$. Larvae were washed again six times with PBS-T and finally mounted in Vectashield (Vector Laboratories).

For DAP treatment, freshly hatched Canton-S flies were collected and placed on a normal food medium containing $600 \mu \mathrm{M}$ of 2,6 Diaminopurine (DAP) (Sigma aldrich 247847). After 5 days, third instar larvae were dissected and subjected to NMJ staining.

Images from muscles 6-7 (segment A2-A3) were acquired with a Zeiss LSM 710 confocal microscope. Serial optical sections at $1,024 \times 1,024$ pixels with $0.4 \mu \mathrm{m}$ thickness were obtained with the $\times 40$ objective. Bouton number was quantified using Imaris 9 software. ImageJ software was used to measure the muscle area and the NMJ axon length and branching. Statistical tests were performed in GraphPad (PRISM 8).

\section{Drosophila behavior assays}

Flies were raised at $25^{\circ} \mathrm{C}$ for associative memory assays and the corresponding controls. All behavior experiments were performed on young adults (1-3 day-old). All behavior experiments were performed on starved flies, which is a prerequisite for appetitive conditioning with a sucrose reinforcement. 0-2 days after hatching, flies were put on starvation for $21 \mathrm{~h}$ at $25^{\circ} \mathrm{C}$ on mineral water (Evian). Appetitive memory assay: Appetitive 
associative conditioning was performed in custom-designed barrel-type apparatus as previously described $\left({ }^{49}\right)$, which allows the parallel conditioning of three groups of flies. The odorants 3-octanol and 4-methylcyclohexanol, diluted in paraffin oil at a final concentration of $0,29 \mathrm{~g} \cdot \mathrm{L}^{-1}$, were used for conditioning and for the test of memory retrieval. Groups of 20-50 flies were subjected to one cycle of appetitive olfactory conditioning as follows: throughout the conditioning protocol, flies were submitted to a constant air flow at 0,6 L $\cdot \mathrm{min}^{-1}$. After $90 \mathrm{~s}$ of habituation, flies were first exposed to an odorant (the $\mathrm{CS}^{+}$) for $1 \mathrm{~min}$ while given access to dried sucrose; flies were then exposed $45 \mathrm{~s}$ later to a second odorant without shocks (the $\mathrm{CS}^{-}$) for $1 \mathrm{~min}$. 3-octanol and 4-methylcyclohexanol were alternately used as $\mathrm{CS}^{+}$and $\mathrm{CS}^{-}$. The memory test was performed in a T-maze apparatus. Each of the two arms of the T-maze were connected to a bottle containing one odorant (either 3-octanol or 4-methylcyclohexanol) diluted in paraffin oil. The global air flow from both arms of the T-maze was set to $0,8 \mathrm{~L} \cdot \mathrm{min}^{-1}$. Flies were given $1 \mathrm{~min}$ in complete darkness to freely move within the T-maze. Then flies from each arm were collected and counted. The repartition of flies was used to calculate a memory score as $\left(\mathrm{N}_{\mathrm{CS}_{+}-} \mathrm{N}_{\mathrm{Cs}-}\right) /\left(\mathrm{N}_{\mathrm{CS}+}+\mathrm{N}_{\mathrm{Cs}-}\right)$. A single performance index value is the average of two scores obtained from two groups of genotypically identical flies conditioned in two reciprocal experiments, using either odorant as the $\mathrm{CS}^{+}$. Thus values of performance index range between -1 and +1 , the value of 0 (equal repartition) corresponding to 'no memory'. The indicated ' $n$ ' is the number of independent performance index values for each genotype. LTM performance was assessed $24 \mathrm{hrs}$ (+/- $2 \mathrm{hrs}$ ) after conditioning, STM $1 \mathrm{hr}$ (+/- $30 \mathrm{~min}$ ) after conditioning. Innate odor avoidance and sucrose attraction assay: Innate sucrose preference was measured in a T-maze. Flies were given the choice for $1 \mathrm{~min}$ between one arm of the T-maze coated with dried sucrose, and one empty arm. There was no air flow in the T-maze for this assay. Flies were then collected from each arm and counted; an attraction index was calculated as $\left(\mathrm{N}_{\text {sucrose }}-\mathrm{N}_{\text {empty }}\right) /\left(\mathrm{N}_{\text {sucrose }}+\mathrm{N}_{\text {empty }}\right)$. The side of the T-maze with sucrose was alternated between experimental replicates. Innate odor avoidance was measured in a T-maze. One arm of the T-maze was connected to a bottle containing the tested odorant (3-octanol or 4-methylcyclohexanol) diluted in paraffin oil, the other arm was connected to a bottle containing paraffin oil only. The global air flow from both arms of the T-maze was set to $0,8 \mathrm{~L} \cdot \mathrm{min}^{-1}$. Flies were given $1 \mathrm{~min}$ in complete darkness to freely move within the T-maze. Flies were then collected from each arm and counted; an avoidance index was calculated as $\left(\mathrm{N}_{\text {air }}-\mathrm{N}_{\text {odor }}\right) /\left(\mathrm{N}_{\text {air }}+\mathrm{N}_{\text {odor }}\right)$. The side of the T-maze with odorant-interlaced air was alternated between experimental replicates. Quantification and statistical analysis: All data are presented as mean \pm SEM. Performances from different groups (mutant and control) were statistically compared using two-tailed unpaired t-test. 


\section{RESULTS}

\section{Comprehensive identification of human FTSJ1 tRNA targets}

To identify new tRNA targets of human FTSJ1, we compared the Nm modification profiles of positions 32 and 34 for all detectable tRNA species on human LCLs obtained from control individuals $(n=4)$ vs. LCLs obtained from individuals with ID harboring loss-of-function and pathogenic variants in FTSJ1 ( $n=5$, from four unrelated families) (Table 1). Four of these affected individuals were already described and harbour distinct molecular defects: a splice variant leading to a premature stop codon ${ }^{39}$ (LCL65AW and LCL65JW), a deletion encompassing FTSJ1 and its flanking gene SLC38A5 ${ }^{40}$ (LCL11), and a missense variant (p.Ala26Pro) affecting an amino acid located close to FTSJ1 catalytic pocket, resulting in the loss of $\mathrm{Gm}_{34}$, but not of $\mathrm{Cm}_{32}$ in human tRNA ${ }^{\text {Phe }}{ }^{23}$ (LCL22). The last individual was not reported nor characterized before. This patient presents mild ID and behavioral manifestations and harbours a de novo pathogenic variant affecting the consensus acceptor splice site of exon 6 (NM_012280.3: c.362-2A>T) (LCL-MM). This mutation leads to the skipping of exon 6 in the mRNA (r.362_414del) leading to a frameshift and a premature stop codon (p.Val121Glyfs ${ }^{*} 51$ ) (Figure S1A). FTSJ1 mRNA steady state level in LCL-MM was significantly reduced when compared to $L C L$ from control individuals (Figure S1B). In addition, treating the LCL-MM cells with cycloheximide to block translation, and thus the nonsense mediated mRNA decay (NMD) pathway ${ }^{50}$, led to an increase of FTSJ1 mRNA abundance (Figure S1C). This result suggests that FTSJ1 mRNA from LCL-MM cells is likely degraded via the NMD pathway.

To obtain a comprehensive picture of the Nm-MTase specificity for FTSJ1 in vivo, we performed RiboMethSeq analysis on LCLs isolated from affected individuals described above and compared with LCL from healthy individuals. RiboMethSeq allows tRNA-wide Nm detection based on random RNA fragmentation by alkaline hydrolysis followed by library preparation and sequencing ${ }^{8}$ (for details see Material and Methods). Using this approach, we could confirm the known FTSJ1 targets (tRNA ${ }^{\text {Phe(GAA) }}$ and $\operatorname{tRNA}^{\operatorname{Trp}(\mathrm{CCA})}$ ) and assign the FTSJ1-deposited $\mathrm{Nm}$ modifications to their predicted positions in the ACL $\left(\mathrm{C}_{32}\right.$ and $\mathrm{N}_{34}$, Figure 1). However, we could not detect a variation for $\mathrm{Cm}_{32}$ in $\mathrm{tRNA}^{\mathrm{Ph}(\mathrm{GAA})}$. The analysis of this position is challenging as we previously reported that the hyper-modification on position 37 of $t R N A^{\text {Phe }}\left(02 \mathrm{yW}_{37} / \mathrm{m}^{1} \mathrm{G}_{37}\right)$ impairs reverse transcription, thereby reducing the number of cDNAs spanning the ACL. Nevertheless, when looking at raw reads count profile, reads at position $33\left(\mathrm{Cm}_{32}\right)$ were increased in FTSJ1 mutated cells (Figure S1D), strongly suggesting a loss of $\mathrm{Cm}_{32}$ of tRNA ${ }^{\mathrm{Phe}(\mathrm{GAA})}$ in FTSJ1 mutated LCLs. Importantly, we identified novel and 
unexpected tRNA targets for human FTSJ1: $\mathrm{Cm}_{32} \operatorname{tRNA}^{\mathrm{Arg}(\mathrm{UCG})}, \mathrm{Cm}_{32} \mathrm{tRNA}^{\mathrm{Gl}(\mathrm{ln} U \mathrm{G})}$ and $\mathrm{Um}_{32}$ tRNA ${ }^{\text {Gly(CCC) }}$ (Table 2).

\section{FTSJ1 loss of function deregulates mRNAs steady state level}

To obtain insights into the impact of FTSJ1 loss on gene expression, we performed a transcriptome analysis in patient and control LCLs. Transcript differential expression analysis shows that FTSJ1 dysfunction led to a deregulation of 686 genes (Table 3 and Figures S2A and S2B). This relatively low number is in agreement with a previous report showing 775 genes deregulated in human HeLa cells knock-down for FTSJ1 ${ }^{51}$, as well as with the 110 mRNAs deregulated in KD of one FTSJ1 Drosophila ortholog ${ }^{28}$.

Even though LCLs do not have a neural origin, analysis of the genes deregulated in affected individuals revealed a clear enrichment (FE $=7.9$ with $p$-value $=7.44 \mathrm{E}-06$ and FDR $=4.40 \mathrm{E}-03$ ) in biological process Gene Ontology (GO) term corresponding to brain morphogenesis (Figure 2A). In addition, and similarly to what we reported in a previous mRNA-seq analysis of Drosophila S2 cells knocked-down for Trm7_34 ${ }^{28}, 5$ out of the top 10 most enriched terms were related to mitochondrial biological processes. Also, in agreement with a recently described role of human FTSJ1 in translational control ${ }^{51,52}$ and of yeast Trm7 in the general amino-acid control pathway ${ }^{31}$, four biological processes related to translation were affected in FTSJ1 mutated LCLs (FE >3.5, Figure 2A).

To confirm the transcriptome analysis, we selected three representative and disease-relevant deregulated mRNAs based on their fold change level of expression and related involvement in brain or cancer diseases. Mutations in the human ZNF711 gene were previously reported to be involved in the development of ID ${ }^{53}$. The mRNA-seq and RT-qPCR analyses showed a significant downregulation of ZNF711 mRNA in FTSJ1 mutant LCLs when compared to control LCLs (Table 3 and Figure 2B). BTBD3 activity is known to direct the dendritic field orientation during development of the sensory neuron in mice cortex ${ }^{54}$ and to regulate mice behaviours ${ }^{55}$. We found that $B T B D 3$ mRNA was significantly upregulated in both mRNA-seq and RT-qPCR analyses (Figure 2B). Lastly, SPARC ${ }^{56}$ and more recently FTSJ1 ${ }^{19,57}$ gene products activities were proposed to be involved in both metastasis and tumour suppression. In the absence of FTSJ1, we could confirm that SPARC mRNA was significantly reduced (Table 3 and Figure 2B). Taken together, these results show deregulation of some mRNAs linked to cancer and brain functioning in FTSJ1 affected individuals' blood derived LCLs.

\section{FTSJ1 loss of function affects the miRNA population}

Our previous work on the Drosophila homologs of FTSJ1, Trm7_32 and Trm7_34, showed that their loss of functions led to perturbations in the small non-coding RNA 
(sncRNA) gene silencing pathways, including the miRNA population ${ }^{28}$. To address whether such perturbations are conserved in NSXLID affected individuals we performed small RNA sequencing on the 5 LCLs carrying FTSJ1 loss-of-function variants compared to the 4 LCLs from control individuals. The principal component analysis (PCA) from the different FTSJ1 loss-of-function cell lines shows a high similarity and thus clusters on the PCA plot, while the wild type lines were more dispersed, possibly explained by their geographic origins and/or age of cell line generation (Figure S3A). The DESeq2 differential expression analysis showed statistically significant deregulation of 36 miRNAs when comparing FTSJ1 mutants to control LCLs. 17 miRNA were up- and 19 down-regulated (Figures 3A, S3B and Table S1). Importantly, as already reported in Drosophila, the global miRNA distribution was not drastically affected, thus ruling out general involvement of FTSJ1 in miRNA biogenesis.

Next, we sought for possible links between the 36 significantly deregulated miRNAs in FTSJ1 mutant cells and neuronal functions or neurodevelopmental disorders. Interestingly, 21 of these miRNAs were already identified in other small RNA-seq studies performed in the context of brain diseases such as epilepsy, Parkinson's and Alzheimer's diseases ${ }^{58-61}$. In addition, 29 of the deregulated miRNAs were linked to different types of cancers 62-67, including 21 involved specifically in brain-related cancers, mostly in glioblastoma ${ }^{62,68-70}$ (Figure 3B and Table 4).

To validate the small RNA-seq data, four hemizygous FTSJ1 LCLs (control) and five LCLs mutants for FTSJ1 were analyzed by northern blotting with a specific probe complementary to miRNA-181a-5p. We selected this miRNA as it was highly upregulated in our transcriptome analysis and it was previously reported to be involved in vascular inflammation and atherosclerosis ${ }^{71}$, as well as expressed in neuronal cells in mammals ${ }^{72}$. One clear hybridization signal was observed in all FTSJ1 mutant LCLs corresponding to mature miRNA-181a-5p (Figure 3C). In contrast, the 4 control LCLs show no or weak signal even after image over-exposure (Figures $3 \mathrm{C}$ ). Together these results demonstrate that FTSJ1 loss of function affects specifically the steady state levels of some miRNA and suggests that the deregulation of miRNA-mediated gene silencing observed in FTSJ1 mutant LCLs was not caused by a global failure in miRNA biogenesis (Figures 3A, S3B and Table S1).

\section{FTSJ1 deregulated miRNAs target FTSJ1 deregulated mRNAs}

As some of the FTSJ1 deregulated miRNAs and mRNAs were implicated in similar biological processes such as cancer and brain function, we wondered if there were some miRNA::mRNA pairs that could be involved in these commonly deregulated processes. Using miRNet 2.0, we performed a bioinformatics cross-analysis of the small RNA-seq and mRNA-seq datasets. We found a subset of FTSJ1-deregulated miRNAs that were previously 
shown to modulate some of the FTSJ1 deregulated mRNAs. For instance, the SPARC mRNA is an experimentally confirmed target of mir-10a-5p ${ }^{73,74}$. This result thus suggests that SPARC mRNA downregulation observed in FTSJ1 mutants may be due to its increased silencing by the upregulated miR-10a-5p. This cross-analysis also revealed that the BTBD3 gene is potentially targeted by miR-181a- $5 p^{75}$, the two of which were upregulated in NSXLID affected individuals-derived LCLs (Figures $3 \mathrm{~A}, 3 \mathrm{C}$ and Table 4), implicating a possible connexion between them that differs from the canonical miRNA silencing pathway. Despite the fact that 39 ZNF mRNAs were found potentially regulated by miR-181a-5p and the over-representation of this miRNA in FTSJ1 mutant, no evidence of miRNA regulation was found for ZNF711 mRNA.

\section{FTSJ1 is involved in human neuronal morphology during development}

The loss of FTSJ1 in humans gives rise to ID, yet the underlying mechanism is still unclear. Both neuronal morphology ${ }^{76}$ and behaviour ${ }^{27}$ have been reported in patients affected by a wide range of ID disorders, with a variety of genetic etiologies and their corresponding mouse models. To address whether loss of human FTSJ1 also affects neuronal morphology, we altered FTSJ1 activity using 2,6-Diaminopurine (DAP) ${ }^{77,78}$ in human Neural Progenitor Cells (NPC). DAP is a recently discovered drug that specifically inhibits FTSJ1 function. Immunostainings were performed for Sox2, a transcription factor expressed in NPCs, and Doublecortin (DCX), an associated microtubule protein expressed in differentiating NPCs or immature neurons, reflecting neurogenesis. Importantly, the DAP treatment did not significantly affect the differentiation of the NPCs (DCX-) to immature neurons $(D C X+)$ (Figure $4 A)$. This is in agreement with previous reports showing the absence of severe brain morphological defects in mice mutated for FTSJ1 ${ }^{27,52}$. However DCX positive cells treated with DAP showed a $25 \%$ increase in the number of interstitial protrusions, likely filopodia, on their neurites compared to the smoother appearance of the neurites of untreated control cells (Figures 4B and 4C). These spines' morphological defects on DCX+ cells are reminiscent of those observed on mature neurons from mutant mice of the Fragile $X$ mental retardation protein (FMRP) ${ }^{79}$, as well as from human patients' brains that suffer from the fragile $X$ syndrome. Furthermore similar findings were recently reported in mice brains mutated for FTSJ1 ${ }^{52}$, suggesting that this is a conserved phenotypic consequence of the loss of FTSJ1.

\section{Drosophila FTSJ1 ortholog is involved in neuronal morphology during development}

To further address whether the control of neuron morphology by FTSJ1 is a conserved feature across evolution we dissected the neuromuscular junctions (NMJs) of Drosophila larvae carrying mutations in the orthologs of the FTSJ1 gene as well as larvae 
fed with DAP 77,78 . Examination of the NMJs in Trm7_32 and Trm7_34 double homozygous mutant larvae or larvae fed with DAP revealed a significant synaptic overgrowth when compared to control larvae (Figure 5). Furthermore, as observed for the human NPC treated with DAP (Figures 4B and 4C), the neurite branching was strongly increased in both, double mutant and fed treated larvae (Figure 5). However the overall length of the axons was not significantly altered. These results indicate that Drosophila FTSJ1s, alike human FTSJ1, control neuronal morphology.

\section{Reward learning requires FTSJ1 activity in Drosophila}

FTSJ1 loss of function affected individuals suffer from significant limitations both in intellectual functioning and in adaptive behavior. Similar phenotypes including impaired learning and memory capacity were recently observed in FTSJ1 KO mice that also present a reduced body weight and bone mass, as well as altered energy metabolism ${ }^{27,52}$. In flies, we recently showed that the loss of FTSJ1 orthologs causes reduced lifespan and body weight, as well as locomotion defect ${ }^{28}$. To address whether fly memory was also altered in these mutants we applied the appetitive conditioning assay. We found that short-term memory (STM) of single Trm7_34 mutant flies was indistinguishable from that of wild-type controls (Figure 6B). However, long-term memory (LTM) was significantly impaired in Trm7_34 mutant flies (Figure 6A). Importantly, naive mutant flies behave normally when exposed to repellent odors used in the olfactory memory assay and detected sugar properly (Figures 6D and $6 \mathrm{C}$ ), suggesting that the LTM defect was not due to a confounding alteration of sensory abilities. Thus, these results indicate that the Drosophila FTSJ1 ortholog has a specific function in LTM. 


\section{DISCUSSION}

In this study, we characterized at the molecular and cellular levels the effect of FTSJ1 loss of function in human cells. We used the innovative RiboMethSeq method to analyse the $\mathrm{Nm}$ status from five patients carrying distinct loss of FTSJ1 functions, which led us to the identification of new FTSJ1 tRNA targets. Furthermore we identify specific transcripts and miRNA that are misregulated in the absence of FTSJ1, that may contribute to the FTSJ1 pathologies, and suggest potential cross-regulation among them. Lastly we show for the first time that the lack of FTSJ1 alters the morphology of human neurons, a phenotype that is conserved in Drosophila and is associated with long term memory deficit.

The power of the RiboMethSeq approach is that it allows to analyse the Nm status of the totality of tRNA species and not only selected tRNAs based on the prior but incomplete knowledge of FTSJ1 targets. Furthermore, this approach covers the whole tRNA-ome and thus can identify variations in $\mathrm{Nm}$ at the single nucleotide resolution, which is very useful to distinguish tRNA isoacceptors for instance that differ by only few nucleotides. By contrast, previously used mass spectrometry-based approaches, although very powerful and sensitive, require the hydrolysis of the tested tRNA into short fragments or single nucleotides, thus the information for the position of these nucleotides in the whole molecule is lost. In order to recover the position of the modified nucleotides, MS approaches count on the available knowledge of specific tRNAs sequences and modification profiles, which are listed in RNA modification databases. Yet the latter are not necessarily exhaustive as evidenced by the continuous discovery of new modified RNA positions in several model organisms, including in human cells.

Our results from the RiboMethSeq performed on patient and control LCLs confirmed the already known human tRNA targets of FTSJ1. For instance, $\mathrm{Cm}_{32}$ and $\mathrm{Cm}_{34}$ of tRNA $^{\operatorname{Trp}(\mathrm{CCA})}$ as well as position 34 in $\operatorname{tRNA}^{\text {Phe(GAA) }}$ and $\operatorname{tRNA}^{\mathrm{Leu}(\mathrm{CAG})}$ were validated by our approach. Only $\mathrm{Cm}_{32}$ of $\mathrm{tRNA} \mathrm{A}^{\mathrm{Phe}(\mathrm{GAA})}$, which is a well-known target of FTSJ1, could not be validated at the first glance. The analysis of this position is challenging due to low read numbers necessary for its quantification. This is the result of two confounding factors. On one hand the calculation of MethScores (Figure $1 \mathrm{~A}$ ) is based on the two neighboring nucleotides ${ }^{38}$. Since FTSJ1 deposits $\mathrm{Nm}$ at both 32 and 34 positions in tRNA ${ }^{\text {Phe }}$, the calculated MethScore at position 32 is affected when position 34 of the same tRNA is also $\mathrm{Nm}$ modified. Second, we previously reported that tRNA ${ }^{\text {Phe(GAA) }}$ ACL positions are challenging to detect due to the specific hyper-modification on position 37 of tRNA ${ }^{\text {Phe } 28}$. Indeed, o2yW $\mathrm{VW}_{37} /$ $\mathrm{m}^{1} \mathrm{G}_{37}$ impairs reverse transcription thereby reducing the number of cDNAs spanning the ACL. Nevertheless, deeper inspection of the raw reads profile shows that $\mathrm{Nm}$ at position 32 
was indeed lost in FTSJ1 mutated cells when compared to control LCL (Figure S1D, confirming the previous reports.

Importantly, we identified novel and unexpected tRNA targets for human FTSJ1: $\mathrm{Cm}_{32} \operatorname{tRNA}^{\mathrm{Arg}(U C G)}, \mathrm{Cm}_{32} \operatorname{tRNA}^{\mathrm{GIn}(\mathrm{CUG})}$ and $\mathrm{Um}_{32} \operatorname{tRNA}^{\mathrm{Gly}(\mathrm{CCC})}$. In the case of $\operatorname{tRNA}{ }^{\mathrm{Arg}(U C G)}$, we uncovered not only a new target for FTSJ1, but also a modification which was not previously reported. Indeed $\mathrm{Cm}_{32}$ was known only for the two other isoacceptors (tRNA ${ }^{\operatorname{Arg}(\mathrm{CCU})}$ and tRNA $\left.^{\mathrm{Arg}(\mathrm{UCU})}\right)^{37}$. Similarly, there was no evidence for a human $\mathrm{Cm}_{32} \operatorname{tRNA}^{\mathrm{Gln}(\mathrm{CUG})}$ and only the other isoacceptor tRNA ${ }^{\text {Gln(UUG) }}$ was reported in Modomics as 2'-O-methylated at $C_{32}$. Still, $\mathrm{Cm}_{32}$ on tRNA ${ }^{\mathrm{Gln}(\mathrm{CUG})}$ was recently discovered as a target of Drosophila Trm7_32 ${ }^{28}$. Among the newly uncovered FTSJ1 targets in this study, $U_{32} \mathrm{tRNA}^{\mathrm{Gly}(\mathrm{CCC})}$ was the only one that has been reported in Modomics, however the enzyme responsible for this modification was unknown. Our results demonstrate that FTSJ1 is the dedicated Nm-Mtase that modified $U$ at position 32 on tRNA ${ }^{\text {Gly(CCC). }}$.

Our transcriptomic analysis also highlighted novel transcripts and miRNA targets that may play important role in the development of the diseases. For instance we found 36 differentially expressed miRNAs, most of which were already associated with brain diseases and functioning and/or cancer development. Strikingly, the most prevalent associated cancer types were the ones related to the brain tissues. Consistently with the post-transcription regulation role of miRNA, we also found through mRNA-seq an enrichment of brain morphogenesis-related mRNAs differentially expressed in FTSJ1 loss of function when compared to control LCLs. Interestingly, a cross-analysis of these two RNA sequencing experiments revealed potential miRNA::target mRNA couples among the deregulated RNA populations. This is indicative of possible miRNA silencing changes in the absence of FTSJ1, similarly to what we report earlier in Drosophila FTSJ1 mutant orthologs. The predicted miRNA::mRNA couples need to be further validated individually in neuronal tissues, although their report from miRnet database (https://www.mirnet.ca/) already includes experimental evidence on the miRNA::mRNA regulation, particularly for BTBD3 and SPARC mRNAs ${ }^{73-75}$.

Affected individuals carrying mutations in FTSJ1 suffer from ID ${ }^{23,39,80}$ but the mechanism underlying this pathology has remained elusive. A recent report from Nagayoshi et al. added some insight by showing that Ftsj1 loss of function in mice provoke dendritic spine overgrowth at hippocampus and cortex neurons ${ }^{52}$, suggesting that a similar alteration of neuron morphology may exist in human patients, which might impair their functioning. Indeed we observed long, thin dendritic spine in human neurons affected for FTSJ1 activity. A similar observation was described earlier for FMRP mutant mice ${ }^{79}$ and FMRP human affected individuals' brains suffering from ID ${ }^{81}$. More examples of improper neuron morphology and in particular spine immaturity were found in additional gene loss of functions 
causative of ID ${ }^{82}$. This suggests that the lack of proper neuronal morphology may be a common feature of ID. More work will be required to address how these changes in spine arborization occur in the absence of FTSJ1 and how this translate into the disease. Interestingly in this study we found that $B T B D 3$ mRNA is significantly upregulated in FTSJ1 mutated LCLs. Since BTBD3 controls dendrite orientation in mammalian cortical neurons ${ }^{54}$ it will be an interesting target to further characterize in the context of FTSJ1 ID pathology.

A synaptic overgrowth was also observed in Drosophila, indicating that this function of FTSJ1 is conserved across evolution. In addition we found that the long term memory but not the short term was significantly altered in the absence of FTSJ1 in flies. This is consistent with the learning deficits observed in mice and humans. In contrast to Human FTSJ1 and the yeast ortholog TRM7, Drosophila uses two distinct paralogs to methylate positions 32 and 34, respectively, on tRNAs ACL. Interestingly, we found that the lack of Trm7_34 had an effect on memory, suggesting that the methylation at wobble position 34 is critical for this function. This hypothesis is strongly supported by the affected individual that harbours a missense variant (p.Ala26Pro, LCL22 in this study), resulting in loss of $\mathrm{Gm}_{34}$, but not of $\mathrm{Cm}_{32}$ in human tRNA ${ }^{\text {Phe } 23}$. Further studies should aim to understand how the loss of methylation at this wobble position affects the learning and memory functions.

The heterogeneity of ID makes it extremely challenging for genetic and clinical diagnosis ${ }^{83}$. Our RiboMethSeq and transcriptomics approaches performed on NSXLID affected individuals have with high confidence extended the panel of FTSJ1's targets. Since our investigation was carried out on LCLs derived from the blood of affected individuals, our resource provides potential new biomarkers for diagnosis of FTSJ1-related ID in the future. For instance, miR-181a-5p, which is detected only in patient derived blood cells, constitutes already a good candidate for such purpose. Therefore our study highlights the usefulness of companion diagnostics in clinical settings, in addition to exome sequencing, for potential discovery of prognostic markers of complex diseases. 


\section{DESCRIPTION OF SUPPLEMENTAL DATA}

Supplemental Data include 8 figures and 1 table.

\section{DECLARATION OF INTERESTS}

The authors declare no competing interests.

\section{ACKNOWLEDGMENTS}

We thank the patients and their families for their participation in the study. We also thank Christelle Thibaut-Charpentier from the GenomEast sequencing platform in Strasbourg, a member of the 'France Génomique' consortium (ANR-10-INBS-0009), the Institut de Génétique Médicale d'Alsace for their technical support and Myriam Bronner from Nancy University Hospital for the establishment of the LCL-MM line. We thank Johann Schor and Laura Guédon for their help with behavioral experiments. Human NPC work was carried out at ICM's CELIS core facility and NPC imaging at the ICM Quant facility. We thank the members of the TErBio laboratory for helpful discussions and reading of the manuscript. C.C. received financial support from the CNRS, Sorbonne Université, the Fondation Maladies Rares (Genomics-2018 \#11809 \& Genomics-2020 \#12824), the IBPS-2020 Action Incitative and the Ligue National contre le cancer Île de France (RS21/76-29). Work in the B.A.H. lab was supported by the Investissements d'Avenir program (ANR-10-IAIHU-06), Paris Brain Institute-ICM core funding, the Roger De Spoelberch Foundation Prize and a grant from the Neuro-Glia Foundation. Research in the laboratory of J.-Y.R. is supported by University of Lausanne and the Deutsche Forschungsgemeinschaft RO 4681/9-1, RO4681/12-1 and RO4681/13-1. D.G.D. and M.B. have PhD fellowships from the Ministère de la Recherche et de l'Enseignement Supérieur at the doctoral school Complexité du Vivant (ED515). We also thank the Fondation ARC pour la Recherche sur le Cancer for funding support to D.G.D. and M.T.A 4th years PhD; 'Réseau André Picard', the 'Société Française de Génétique' (to M.B., M.T.A and D.G.D.) and COST action 'EPITRAN' CA16120 (to Y.M., J.Y.R., V.M., D.G.D., M.B., M.T.A and C.C.) for traveling and training fellowships.

\section{DATA AND CODE AVAILABILITY}

The RNA sequencing and small RNA sequencing data discussed in this publication will be deposited and fully accessible before publication and upon request during the reviewing process, either in NCBl's Gene Expression Omnibus accessible through GEO Series accession number $\mathrm{XXX}$ (https://www.XXX) or at the European Nucleotide Archive (ENA) at EMBL-EBI under accession number XXX (https://www.XXX). 


\section{REFERENCES}

1. Saletore, Y., Meyer, K., Korlach, J., Vilfan, I.D., Jaffrey, S., and Mason, C.E. (2012). The birth of the Epitranscriptome: deciphering the function of RNA modifications. Genome Biol. 13, 175.

2. Angelova, M.T., Dimitrova, D.G., Dinges, N., Lence, T., Worpenberg, L., Carré, C., and Roignant, J.-Y. (2018). The Emerging Field of Epitranscriptomics in Neurodevelopmental and Neuronal Disorders. Front Bioeng Biotechnol 6, 46. 3. Zhao, L.-Y., Song, J., Liu, Y., Song, C.-X., and Yi, C. (2020). Mapping the epigenetic modifications of DNA and RNA. Protein Cell.

4. Kawai, G., Yamamoto, Y., Kamimura, T., Masegi, T., Sekine, M., Hata, T., limori, T., Watanabe, T., Miyazawa, T., and Yokoyama, S. (1992). Conformational rigidity of specific pyrimidine residues in tRNA arises from posttranscriptional modifications that enhance steric interaction between the base and the 2'-hydroxyl group. Biochemistry 31, 1040-1046.

5. Kurth, H.M., and Mochizuki, K. (2009). 2'-O-methylation stabilizes Piwi-associated small RNAs and ensures DNA elimination in Tetrahymena. RNA 15, 675-685.

6. Lacoux, C., Di Marino, D., Boyl, P.P., Zalfa, F., Yan, B., Ciotti, M.T., Falconi, M., Urlaub, H., Achsel, T., Mougin, A., et al. (2012). BC1-FMRP interaction is modulated by 2'-O-methylation: RNA-binding activity of the tudor domain and translational regulation at synapses. Nucleic Acids Research 40, 4086-4096.

7. Erales, J., Marchand, V., Panthu, B., Gillot, S., Belin, S., Ghayad, S.E., Garcia, M., Laforêts, F., Marcel, V., Baudin-Baillieu, A., et al. (2017). Evidence for rRNA 2'-O-methylation plasticity: Control of intrinsic translational capabilities of human ribosomes. Proc. Natl. Acad. Sci. U. S. A. 114, 12934-12939.

8. Marchand, V., Pichot, F., Thüring, K., Ayadi, L., Freund, I., Dalpke, A., Helm, M., and Motorin, Y. (2017). Next-Generation Sequencing-Based RiboMethSeq Protocol for Analysis of tRNA 2'-O-Methylation. Biomolecules 7, 13.

9. Darzacq, X. (2002). Cajal body-specific small nuclear RNAs: a novel class of 2'-O-methylation and pseudouridylation guide RNAs. The EMBO Journal 21, 2746-2756.

10. Dai, Q., Moshitch-Moshkovitz, S., Han, D., Kol, N., Amariglio, N., Rechavi, G., Dominissini, D., and $\mathrm{He}, \mathrm{C}$. (2017). Nm-seq maps 2'-O-methylation sites in human mRNA with base precision. Nature Methods 14, 695-698.

11. Li, J., Yang, Z., Yu, B., Liu, J., and Chen, X. (2005). Methylation Protects miRNAs and siRNAs from a 3'-End Uridylation Activity in Arabidopsis. Curr. Biol. 15, 1501-1507.

12. Yu, B., Yang, Z., Li, J., Minakhina, S., Yang, M. Padgett, R.W., Steward, R., and Chen, X. (2005). Methylation as a crucial step in plant microRNA biogenesis. Science 307, 932-935.

13. Horwich, M.D., Li, C., Matranga, C., Vagin, V., Farley, G., Wang, P., and Zamore, P.D. (2007). The Drosophila RNA methyltransferase, DmHen1, modifies germline piRNAs and single-stranded siRNAs in RISC. Curr. Biol. 17, 1265-1272.

14. Saito, K., Sakaguchi, Y., Suzuki, T., Suzuki, T., Siomi, H., and Siomi, M.C. (2007). Pimet, the Drosophila homolog of HEN1, mediates 2'-O-methylation of Piwi- interacting RNAs at their 3' ends. Genes Dev. 21, 1603-1608.

15. Kristen M Bartoli, Cassandra Schaening, Thomas Carlile, Wendy V Gilbert Conserved Methyltransferase Spb1 Targets mRNAs for Regulated Modification with 2'-O-Methyl Ribose.

16. Dimitrova, D.G., Teysset, L., and Carré, C. (2019). RNA 2'-O-Methylation (Nm) Modification in Human Diseases. Genes 10,

17. Liu, B., Li, J., Zheng, M., Ge, J., Li, J., and Yu, P. (2017). MiR-542-3p exerts tumor suppressive functions in non-small cell lung cancer cells by upregulating FTSJ2. Life Sci. 188, 87-95.

18. El Hassouni, B., Sarkisjan, D., Vos, J.C., Giovannetti, E., and Peters, G.J. (2019). Targeting the Ribosome Biogenesis Key Molecule Fibrillarin to Avoid Chemoresistance. Curr. Med. Chem. 26, 6020-6032.

19. He, Q., Yang, L., Gao, K., Ding, P., Chen, Q., Xiong, J., Yang, W., Song, Y., Wang, L., Wang, Y., et al. (2020). FTSJ1 regulates tRNA 2'-O-methyladenosine modification and suppresses the malignancy of NSCLC via inhibiting DRAM1 expression. Cell Death Dis. 11, 1-12.

20. Marcel, V., Kielbassa, J., Marchand, V., Natchiar, K.S., Paraqindes, H., Van Long, F.N., Ayadi, L., Bourguignon-Igel, V., Lo Monaco, P., Monchiet, D., et al. (2020). Ribosomal RNA 2 'O-methylation as a novel layer of inter-tumour heterogeneity in breast cancer. NAR Cancer 2,.

21. Jia, Y., Mu, J.C., and Ackerman, S.L. (2012). Mutation of a U2 snRNA gene causes global disruption of alternative splicing and neurodegeneration. Cell 148, 296-308.

22. Abe, M., Naqvi, A., Hendriks, G.-J., Feltzin, V., Zhu, Y., Grigoriev, A., and Bonini, N.M. (2014). Impact of age-associated increase in 2'-O-methylation of miRNAs on aging and 
neurodegeneration in Drosophila. Genes Dev. 28, 44-57.

23. Guy, M.P., Shaw, M., Weiner, C.L., Hobson, L., Stark, Z., Rose, K., Kalscheuer, V.M., Gecz, J., and Phizicky, E.M. (2015). Defects in tRNA Anticodon Loop 2'-O-Methylation Are Implicated in Nonsyndromic X-Linked Intellectual Disability due to Mutations in FTSJ1. Hum. Mutat. 36, 1176-1187.

24. Cavaillé, J. (2017). Box C/D small nucleolar RNA genes and the Prader-Willi syndrome: a complex interplay. Wiley Interdiscip. Rev. RNA 8,.

25. Bügl, H., Fauman, E.B., Staker, B.L., Zheng, F., Kushner, S.R., Saper, M.A., Bardwell, J.C., and Jakob, U. (2000). RNA methylation under heat shock control. Mol. Cell 6, 349-360.

26. Feder, M., Pas, J., Wyrwicz, L.S., and Bujnicki, J.M. (2003). Molecular phylogenetics of the RrmJ/fibrillarin superfamily of ribose 2'-O-methyltransferases. Gene 302, 129-138.

27. Jensen, L.R., Garrett, L., Hölter, S.M., Rathkolb, B., Rácz, I., Adler, T., Prehn, C., Hans, W., Rozman, J., Becker, L., et al. (2019). A mouse model for intellectual disability caused by mutations in the X-linked 2'-O-methyltransferase Ftsj1 gene. Biochimica et Biophysica Acta (BBA) - Molecular Basis of Disease 1865, 2083-2093.

28. Angelova, M.T., Dimitrova, D.G., Da Silva, B., Marchand, V., Jacquier, C., Achour, C., Brazane, M., Goyenvalle, C., Bourguignon-Igel, V., Shehzada, S., et al. (2020). tRNA 2'-O-methylation by a duo of TRM7/FTSJ1 proteins modulates small RNA silencing in Drosophila. Nucleic Acids Res. 48, 2050-2072.

29. Pintard, L., Lecointe, F., Bujnicki, J.M., Bonnerot, C., Grosjean, H., and Lapeyre, B. (2002). Trm7p catalyses the formation of two 2'-O-methylriboses in yeast tRNA anticodon loop. EMBO J. 21, 1811-1820.

30. Guy, M.P., Podyma, B.M., Preston, M.A., Shaheen, H.H., Krivos, K.L., Limbach, P.A., Hopper, A.K., and Phizicky, E.M. (2012). Yeast Trm7 interacts with distinct proteins for critical modifications of the tRNAPhe anticodon loop. RNA $18,1921-1933$

31. Han, L., Guy, M.P., Kon, Y., and Phizicky, E.M. (2018). Lack of 2'-O-methylation in the tRNA anticodon loop of two phylogenetically distant yeast species activates the general amino acid control pathway. PLoS Genet. 14, e1007288.

32. Li, J., Wang, Y.-N., Xu, B.-S., Liu, Y.-P., Zhou, M., Long, T., Li, H., Dong, H., Nie, Y., Chen, P.R., et al. (2020). Intellectual disability-associated gene $\mathrm{ftsj} 1$ is responsible for 2'-O-methylation of specific tRNAs. EMBO Rep. e50095.
33. Noma, A., Kirino, Y., Ikeuchi, Y., and Suzuki, T. (2006). Biosynthesis of wybutosine, a hyper-modified nucleoside in eukaryotic phenylalanine tRNA. EMBO J. 25, 2142-2154.

34. Guy, M.P., and Phizicky, E.M. (2015). Conservation of an intricate circuit for crucial modifications of the tRNAPhe anticodon loop in eukaryotes. RNA 21, 61-74.

35. Kawarada, L., Suzuki, T., Ohira, T., Hirata, S., Miyauchi, K., and Suzuki, T. (2017). ALKBH1 is an RNA dioxygenase responsible for cytoplasmic and mitochondrial tRNA modifications. Nucleic Acids Res. 45, 7401-7415.

36. Chan, P.P., and Lowe, T.M. (2016). GtRNAdb 2.0: an expanded database of transfer RNA genes identified in complete and draft genomes. Nucleic Acids Res. 44, D184-D189.

37. Boccaletto, P., Machnicka, M.A., Purta, E., Piatkowski, P., Baginski, B., Wirecki, T.K., de Crécy-Lagard, V., Ross, R., Limbach, P.A., Kotter, A., et al. (2018). MODOMICS: a database of RNA modification pathways. 2017 update. Nucleic Acids Res. 46, D303-D307.

38. Marchand, V., Blanloeil-Oillo, F., Helm, M., and Motorin, Y. (2016). Illumina-based RiboMethSeq approach for mapping of 2'-O-Me residues in RNA. Nucleic Acids Res. 44, e135.

39. Freude, K., Hoffmann, K., Jensen, L.-R., Delatycki, M.B., des Portes, V., Moser, B., Hamel, B., van Bokhoven, H., Moraine, C., Fryns, J.-P., et al. (2004). Mutations in the FTSJ1 Gene Coding for a Novel S-Adenosylmethionine-Binding Protein Cause Nonsyndromic X-Linked Mental Retardation. Am. J. Hum. Genet. 75, 305-309.

40. Froyen, G., Bauters, M., Boyle, J., Van Esch, H., Govaerts, K., van Bokhoven, H., Ropers, H.-H., Moraine, C., Chelly, J., Fryns, J.-P., et al. (2007). Loss of SLC38A5 and FTSJ1 at Xp11.23 in three brothers with non-syndromic mental retardation due to a microdeletion in an unstable genomic region. Hum. Genet. 121, 539-547.

41. Bolger, A.M., Lohse, M., and Usadel, B. (2014). Trimmomatic: a flexible trimmer for Illumina sequence data. Bioinformatics 30, 2114-2120.

42. Langmead, B., Trapnell, C., Pop, M., and Salzberg, S.L. (2009). Ultrafast and memory-efficient alignment of short DNA sequences to the human genome. Genome Biol. $10, \mathrm{R} 25$

43. Quinlan, A.R. (2014). BEDTools: The Swiss-Army Tool for Genome Feature Analysis. Curr. Protoc. Bioinformatics 47, 11.12.1-34.

44. Pichot, F., Marchand, V., Ayadi, L., Bourguignon-Igel, V., Helm, M., and Motorin, Y. 
(2020). Holistic Optimization of Bioinformatic Analysis Pipeline for Detection and Quantification of 2'-O-Methylations in RNA by RiboMethSeq. Front. Genet. 11, 38.

45. Birkedal, U., Christensen-Dalsgaard, M., Krogh, N., Sabarinathan, R., Gorodkin, J., and Nielsen, H. (2015). Profiling of ribose methylations in RNA by high-throughput sequencing. Angew. Chem. Int. Ed Engl. 54, 451-455.

46. Khalil, A., Medfai, H., Poelvoorde, P., Kazan, M.F., Delporte, C., Van Antwerpen, P., EL-Makhour, Y., Biston, P., Delrée, P., Badran, B., et al. (2018). Myeloperoxidase promotes tube formation, triggers ERK1/2 and Akt pathways and is expressed endogenously in endothelial cells. Arch. Biochem. Biophys. 654, 55-69.

47. Langmead, B., and Salzberg, S.L. (2012). Fast gapped-read alignment with Bowtie 2. Nat. Methods 9, 357-359.

48. Love, M.I., Huber, W., and Anders, S. (2014). Moderated estimation of fold change and dispersion for RNA-seq data with DESeq. 2 Genome Biol 15: 550.

49. Colomb, J., Kaiser, L., Chabaud, M.-A., and Preat, T. (2009). Parametric and genetic analysis of Drosophila appetitive long-term memory and sugar motivation. Genes Brain Behav. 8, 407-415.

50. Tarpey, P.S., Raymond, F.L., Nguyen, L.S., Rodriguez, J., Hackett, A., Vandeleur, L., Smith, R., Shoubridge, C., Edkins, S., Stevens, C., et al. (2007). Mutations in UPF3B, a member of the nonsense-mediated mRNA decay complex, cause syndromic and nonsyndromic mental retardation. Nat. Genet. 39, 1127-1133.

51. Trzaska, C., Amand, S., Bailly, C., Leroy, C., Marchand, V., Duvernois-Berthet, E., Saliou, J.-M., Benhabiles, H., Werkmeister, E., Chassat, T., et al. (2020). 2,6-Diaminopurine as a highly potent corrector of UGA nonsense mutations. Nature Communications 11 ,.

52. Nagayoshi, Y., Chujo, T., Hirata, S., Nakatsuka, H., Chen, C.-W., Takakura, M., Miyauchi, K., Ikeuchi, Y., Carlyle, B.C., Kitchen, R.R., et al. (2021). Loss of Ftsj1 perturbs codon-specific translation efficiency in the brain and is associated with X-linked intellectual disability. Sci Adv 7,.

53. van der Werf, I.M., Van Dijck, A., Reyniers, E., Helsmoortel, C., Kumar, A.A., Kalscheuer, V.M., de Brouwer, A.P., Kleefstra, T., van Bokhoven, H., Mortier, G., et al. (2017). Mutations in two large pedigrees highlight the role of ZNF711 in X-linked intellectual disability. Gene 605, 92-98.

54. Matsui, A., Tran, M., Yoshida, A.C., Kikuchi, S.S., U, M., Ogawa, M., and Shimogori, T. (2013). BTBD3 controls dendrite orientation toward active axons in mammalian neocortex. Science 342, 1114-1118.

55. Thompson, S.L., Welch, A.C., Ho, E.V., Bessa, J.M., Portugal-Nunes, C., Morais, M., Young, J.W., Knowles, J.A., and Dulawa, S.C. (2019). Btbd3 expression regulates compulsive-like and exploratory behaviors in mice. Transl. Psychiatry 9, 222.

56. Tai, I.T., and Tang, M.J. (2008). SPARC in cancer biology: its role in cancer progression and potential for therapy. Drug Resist. Updat. 11, 231-246.

57. Holzer, K., Ori, A., Cooke, A., Dauch, D., Drucker, E., Riemenschneider, P., Andres-Pons, A., DiGuilio, A.L., Mackmull, M.-T., Baßler, J., et al. (2019). Nucleoporin Nup155 is part of the p53 network in liver cancer. Nat. Commun. 10, 2147.

58. Lau, P., Bossers, K., Janky, R. 's, Salta, E., Frigerio, C.S., Barbash, S., Rothman, R., Sierksma, A.S.R., Thathiah, A., Greenberg, D., et al. (2013). Alteration of the microRNA network during the progression of Alzheimer's disease. EMBO Mol. Med. 5, 1613-1634.

59. Kretschmann, A., Danis, B., Andonovic, L., Abnaof, K., van Rikxoort, M., Siegel, F., Mazzuferi, M., Godard, P., Hanon, E., Fröhlich, H., et al. (2015). Different microRNA profiles in chronic epilepsy versus acute seizure mouse models. J. Mol. Neurosci. 55, 466-479.

60. Ding, H., Huang, Z., Chen, M., Wang, C., Chen, X., Chen, J., and Zhang, J. (2016). Identification of a panel of five serum miRNAs as a biomarker for Parkinson's disease. Parkinsonism Relat. Disord. $22,68-73$.

61. Roser, A.E., Caldi Gomes, L., Schünemann, J., Maass, F., and Lingor, P. (2018). Circulating miRNAs as Diagnostic Biomarkers for Parkinson's Disease. Front. Neurosci. 12, 625.

62. Lund, A.H. (2010). miR-10 in development and cancer. Cell Death Differ. 17, 209-214.

63. Watahiki, A., Wang, Y., Morris, J., Dennis, K., O'Dwyer, H.M., Gleave, M., Gout, P.W., and Wang, Y. (2011). MicroRNAs associated with metastatic prostate cancer. PLoS One 6, e24950.

64. Li, Y., Kuscu, C., Banach, A., Zhang, Q., Pulkoski-Gross, A., Kim, D., Liu, J., Roth, E., Li, E., Shroyer, K.R., et al. (2015). miR-181a-5p Inhibits Cancer Cell Migration and Angiogenesis via Downregulation of Matrix Metalloproteinase-14. Cancer Res. 75, 2674-2685.

65. Khuu, C., Sehic, A., Eide, L., and Osmundsen, H. (2016). Anti-proliferative Properties of miR-20b and miR-363 from the miR-106a-363 Cluster on Human Carcinoma Cells. Microrna 5, 19-35. 
66. Yang, C., Tabatabaei, S.N., Ruan, X., and Hardy, P. (2017). The Dual Regulatory Role of MiR-181a in Breast Cancer. Cell. Physiol. Biochem. 44, 843-856.

67. Jiang, C., Cao, Y., Lei, T., Wang, Y., Fu, J., Wang, Z., and Lv, Z. (2018). microRNA-363-3p inhibits cell growth and invasion of non-small cell lung cancer by targeting HMGA2. Mol. Med. Rep. $17,2712-2718$.

68. Gillies, J.K., and Lorimer, I.A.J. (2007). Regulation of p27Kip1 by miRNA 221/222 in glioblastoma. Cell Cycle 6, 2005-2009.

69. Shi, L., Cheng, Z., Zhang, J., Li, R., Zhao, P., $\mathrm{Fu}$, Z., and You, Y. (2008). hsa-mir-181a and hsa-mir-181b function as tumor suppressors in human glioma cells. Brain Res. 1236, 185-193.

70. Conti, A., Romeo, S.G., Cama, A., La Torre, D., Barresi, V., Pezzino, G., Tomasello, C., Cardali, S., Angileri, F.F., Polito, F., et al. (2016). MiRNA expression profiling in human gliomas: upregulated miR-363 increases cell survival and proliferation. Tumour Biol. 37, 14035-14048.

71. Su, Y., Yuan, J., Zhang, F., Lei, Q., Zhang, T., Li, K., Guo, J., Hong, Y., Bu, G., Lv, X., et al. (2019). MicroRNA-181a-5p and microRNA-181a-3p cooperatively restrict vascular inflammation and atherosclerosis. Cell Death Dis. 10, 365.

72. Dostie, J., Mourelatos, Z., Yang, M., Sharma, A., and Dreyfuss, G. (2003). Numerous microRNPs in neuronal cells containing novel microRNAs. RNA 9, 180-186.

73. Bryant, A., Palma, C.A., Jayaswal, V., Yang, Y.W., Lutherborrow, M., and Ma, D.D. (2012). $\mathrm{miR}-10 \mathrm{a}$ is aberrantly overexpressed in Nucleophosmin1 mutated acute myeloid leukaemia and its suppression induces cell death. Mol. Cancer 11,8 .

74. Wang, H., Lin, S.-Y., Hu, F.-F., Guo, A.-Y., and $\mathrm{Hu}, \mathrm{H}$. (2020). The expression and regulation of HOX genes and membrane proteins among different cytogenetic groups of acute myeloid leukemia. Mol Genet Genomic Med 8, e1365.

75. He, S., Zeng, S., Zhou, Z.-W., He, Z.-X., and Zhou, S.-F. (2015). Hsa-microRNA-181a is a regulator of a number of cancer genes and a biomarker for endometrial carcinoma in patients: a bioinformatic and clinical study and the therapeutic implication. Drug Des. Devel. Ther. 9, 1103-1175.

76. Chen, J., Lambo, M.E., Xia, G., Dearborn, J.T., and Liu, Y. (2020). A MYT1L Syndrome mouse model recapitulates patient phenotypes and reveals altered brain development due to disrupted neuronal maturation. bioRxiv.

77. Trzaska, C., Amand, S., Bailly, C., Leroy, C.,
Marchand, V., Duvernois-Berthet, E., Saliou, J.-M., Benhabiles, H., Werkmeister, E., Chassat, T., et al. (2020). 2,6-Diaminopurine as a highly potent corrector of UGA nonsense mutations. Nat. Commun. 11, 1509.

78. Palma, M., and Lejeune, F. (2021). Deciphering the molecular mechanism of stop codon readthrough. Biol. Rev. Camb. Philos. Soc. 96, 310-329.

79. Braun, K., and Segal, M. (2000). FMRP involvement in formation of synapses among cultured hippocampal neurons. Cereb. Cortex 10, 1045-1052.

80. Ramser, J., Winnepenninckx, B., Lenski, C., Errijgers, V., Platzer, M., Schwartz, C.E., Meindl, A., and Kooy, R.F. (2004). A splice site mutation in the methyltransferase gene FTSJ1 in Xp11.23 is associated with non-syndromic mental retardation in a large Belgian family (MRX9). J. Med. Genet. 41, 679-683.

81. Irwin, S.A., Galvez, R., and Greenough, W.T. (2000). Dendritic spine structural anomalies in fragile-X mental retardation syndrome. Cereb. Cortex 10, 1038-1044.

82. Levenga, J., and Willemsen, R. (2012). Perturbation of dendritic protrusions in intellectual disability. Prog. Brain Res. 197, 153-168.

83. Ilyas, M., Mir, A., Efthymiou, S., and Houlden, H. (2020). The genetics of intellectual disability: advancing technology and gene editing. F1000Res. 9, .

84. Risbud, R.M., and Porter, B.E. (2013). Changes in microRNA expression in the whole hippocampus and hippocampal synaptoneurosome fraction following pilocarpine induced status epilepticus. PLoS One 8, e53464.

85. Kan, A.A., van Erp, S., Derijck, A.A.H.A., de Wit, M., Hessel, E.V.S., O'Duibhir, E., de Jager, W., Van Rijen, P.C., Gosselaar, P.H., de Graan, P.N.E., et al. (2012). Genome-wide microRNA profiling of human temporal lobe epilepsy identifies modulators of the immune response. Cell. Mol. Life Sci. 69, 3127-3145.

86. Zhang, C.-Z., Zhang, J.-X., Zhang, A.-L., Shi, Z.-D., Han, L., Jia, Z.-F., Yang, W.-D., Wang, G.-X., Jiang, T., You, Y.-P., et al. (2010). MiR-221 and miR-222 target PUMA to induce cell survival in glioblastoma. Mol. Cancer 9, 229.

87. Ma, W., Li, Y., Wang, C., Xu, F., Wang, M., and Liu, Y. (2016). Serum miR-221 serves as a biomarker for Parkinson's disease. Cell Biochem. Funct. 34, 511-515.

88. Fornari, F., Gramantieri, L., Ferracin, M., Veronese, A., Sabbioni, S., Calin, G.A., Grazi, G.L., 
bioRxiv preprint doi: https://doi.org/10.1101/2021.02.06.430044; this version posted May 22, 2021. The copyright holder for this preprint (which was not certified by peer review) is the author/funder, who has granted bioRxiv a license to display the preprint in perpetuity. It is made available under aCC-BY-NC-ND 4.0 International license.

Giovannini, C., Croce, C.M., Bolondi, L., et al. (2008). MiR-221 controls CDKN1C/p57 and CDKN1B/p27 expression in human hepatocellular carcinoma. Oncogene 27, 5651-5661.

89. Gui, Y., Liu, H., Zhang, L., Lv, W., and Hu, X. (2015). Altered microRNA profiles in cerebrospinal fluid exosome in Parkinson disease and Alzheimer disease. Oncotarget 6, 37043-37053.

90. Tehler, D., Høyland-Kroghsbo, N.M., and Lund, A.H. (2011). The miR-10 microRNA precursor family. RNA Biol. 8, 728-734.

91. Kiyosawa, N., Watanabe, K., Toyama, K., and Ishizuka, H. (2019). Circulating miRNA Signature as a Potential Biomarker for the Prediction of Analgesic Efficacy of Hydromorphone. Int. J. Mol. Sci. 20 ,.

92. Qiao, J., Lee, S., Paul, P., Theiss, L., Tiao, J., Qiao, L., Kong, A., and Chung, D.H. (2013). miR-335 and miR-363 regulation of neuroblastoma tumorigenesis and metastasis. Surgery 154, 226-233.

93. Ye, J., Zhang, W., Liu, S., Liu, Y., and Liu, K. (2017). miR-363 inhibits the growth, migration and invasion of hepatocellular carcinoma cells by regulating E2F3. Oncol. Rep. 38, 3677-3684.

94. Hu, F., Min, J., Cao, X., Liu, L., Ge, Z., Hu, J., and $\mathrm{Li}, \quad X$. (2016). MiR-363-3p inhibits the epithelial-to-mesenchymal transition and suppresses metastasis in colorectal cancer by targeting Sox4. Biochem. Biophys. Res. Commun. $474,35-42$.

95. Wang, S.-H., Zhang, W.-J., Wu, X.-C., Weng, M.-Z., Zhang, M.-D., Cai, Q., Zhou, D., Wang, J.-D., and Quan, Z.-W. (2016). The IncRNA MALAT1 functions as a competing endogenous RNA to regulate $\mathrm{MCL}-1$ expression by sponging miR-363-3p in gallbladder cancer. J. Cell. Mol. Med. 20, 2299-2308.

96. Karatas, O.F., Suer, I., Yuceturk, B., Yilmaz, M., Oz, B., Guven, G., Cansiz, H., Creighton, C.J., Ittmann, M., and Ozen, M. (2016). Identification of microRNA profile specific to cancer stem-like cells directly isolated from human larynx cancer specimens. BMC Cancer 16, 853

97. Chapman, B.V., Wald, A.I., Akhtar, P., Munko, A.C., Xu, J., Gibson, S.P., Grandis, J.R., Ferris, R.L., and Khan, S.A. (2015). MicroRNA-363 targets myosin $1 \mathrm{~B}$ to reduce cellular migration in head and neck cancer. BMC Cancer 15, 861.

98. Zhang, P.-F., Sheng, L.-L., Wang, G., Tian, M., Zhu, L.-Y., Zhang, R., Zhang, J., and Zhu, J.-S. (2016). miR-363 promotes proliferation and chemo-resistance of human gastric cancer via targeting of FBW7 ubiquitin ligase expression. Oncotarget 7, 35284-35292.

99. Zhang, S.-F., Chen, J.-C., Zhang, J., and Xu, J.-G. (2017). miR-181a involves in the hippocampus-dependent memory formation via targeting PRKAA1. Sci. Rep. 7, 8480. 


\section{FIGURES TITLES AND LEGENDS}

Figure 1. FTSJ1 targets multiple tRNAs at positions 32 and 34 in humans. Methylation scores (MethScore) for 2'-O-methylated positions in tRNAs showing altered methylation in FTSJ1 loss-of-function mutant LCLs. MethScore (Score C), representing the level of ribose methylation was calculated from protection profiles. Data are shown for positions 32 and 34 in different $H$. sapiens tRNAs as measured in different LCL lines that are indicated with different colour code. Grey: control LCL; blue: FTSJ1 mutant LCLs.

Figure 2. FTSJ1 loss of function leads to mRNAs deregulation in NSXLID affected individuals LCLs. (A) FTSJ1 loss of function mRNAs GO term. GO analysis of the 686 deregulated genes in FTSJ1 function-deficient LCLs derived from NSXLID affected individuals. The most enriched GO term is brain morphogenesis. GO analysis was performed using http://geneontology.org/. (B) RT-qPCR analysis confirms deregulation in ZNF711, BTBD3 and SPARC mRNAs expression levels. Normalized to GAPDH steady state levels. $\mathrm{n}>3$. $p$-values were calculated with paired Student's $t$-test ${ }^{* *} p<0,01,{ }^{* * *} p<0,001$. WT values: mean of 2 control FTSJ1 LCL. Mutant values: mean of all (x5) FTSJ1 mutant LCLs of this study, or two (LCL MM and LCL 65JW) for ZNF711 qPCR.

Figure 3. FTSJ1 loss of function leads to miRNAs deregulation in NSXLID affected individuals LCLs. (A) Heat map generated using the pheatmap package in $\mathrm{R}$ showing the 36 deregulated miRNAs in FTSJ1 loss of function LCLs compared to controls. Batch points to the country of origin of the LCLs. Condition points to the FTSJ1 LCL status, WT or mutated for FTSJ1 gene. (B) Bibliographic search (Table. 4) of the miRNAs deregulated in FTSJ1 loss of function LCLs reveals evidence for many of them as being implicated in cancers or brain development and brain diseases. The number of miRNAs related to brain, cancer and brain-cancer specifically are indicated respectively in the blue, green and red circle. The Venn diagram was generated by http://bioinformatics.psb.ugent.be/webtools/Venn/. (C) Northern blot analysis with ${ }^{32} \mathrm{P}$-labelled probe specific for hsa-miR-181a-5p confirms the upregulation of this miRNA in FTSJ1 loss of function condition already detected by small RNAseq analysis. A ${ }^{32}$ P-labelled probe specific for human U6 RNA was used to assess equal loading on the blot. Australian and French LCLs point to the country of origin of the LCLs.

Figure 4. FTJS1 depletion affects human neurons' neurite spines morphology. (A) DAP induced FTJS1 inhibition does not affect human NPC to immature neuron differentiation. Immunostainings for DCX and SOX2 were performed on human iPSCs derived NPCs either treated with $100 \mu \mathrm{M}$ DAP or equal volume of $\mathrm{H}_{2} \mathrm{O}$ for $24 \mathrm{~h}$. Cells were numbered on microscopy acquisitions, and the ratio of DCX expressing cells over total cell number was calculated and expressed in fold change. Error bars represent standard deviation of three independent experiments; n.s: not significant (over 1400 cells numbered for a single experiment). (B). Lower

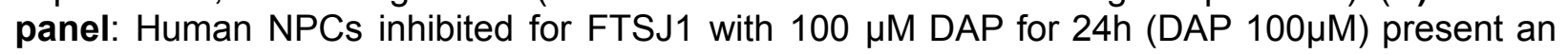
increased number of neurite spines during NPC to immature neuron differentiation. DCX protein expressed in immature neurons is marked in green (DCX). Dashed white line represents the zoom-in zone depicted in the top right corner with a continuous white line. White stars $\left(^{*}\right)$ in the magnified inset point to the fine spine neurites. Upper panel: Untreated NPCs (Control). Nuclear staining was performed using DAPI depicted in blue (DAPI). (C) Quantification of thin spines of DCX positive cells (Figure 4B above). Thin projections were numbered and normalized over the total length of the immature neurons as traced and measured by SNT (Fiji plugin). Quantifications were carried out on 5 acquisitions for each experiment (Control and DAP $100 \mu \mathrm{M})(>40$ branches/acquisition on average). Aggregate of 3 independent experiments. Wilcoxon Mann-Whitney's test ${ }^{* *} \mathrm{P}=0,0098$.

Figure 5. FTSJ1 dependent $\mathrm{Nm}$ regulates axonal growth in the Drosophila nervous system. Left panel: Representative confocal images of muscle-6/7 NMJ synapses of larval abdominal hemisegments A2-A3 for the indicated genotypes labelled with anti-synaptotagmin 
(green) and HRP (red) to reveal the synaptic vesicles and the neuronal membrane. Scale bar: $20 \mu \mathrm{m}$. Right panel: Quantification of normalized bouton number (total number of boutons/muscle surface area (MSA) $\left(\mu \mathrm{m}^{2} \times 1,000\right)$ ) (top), normalized axon length (middle) and normalized branching (bottom) of NMJ 6/7 in A2-A3 of the indicated genotypes. Bars show mean \pm s.e.m. Multiple comparisons were performed using one-way ANOVA with a post hoc Sidak-Bonferroni correction. (n.s. = not significant; ${ }^{*} P<0.05$; ${ }^{* * *} P<0.001 ;{ }^{* * * *} P<0.0001$ ). Bars are labeled with the number of replicates. Canton-S larvae were used as wild-type control.

Figure 6. FTSJ1 Drosophila FTJS1 ortolog Trm7_34 mutants are defective for appetitive long-term memory. (A) Flies were starved on mineral water for $21 \mathrm{hrs}$ and then trained with an appetitive associative olfactory learning protocol (odor paired with sucrose ingestion). Long-Term Memory (LTM) performance was measured $24 \mathrm{hrs}$ after learning. The LTM score of flies mutant for Trm7 34 (Mut Trm7_34 ${ }^{\mathrm{e} 02001}$ ) was severely impaired as compared to their genotypic controls $\left(w^{1118}\right)$ ( $n=14$ per condition; $p=0.0001$; two-tailed unpaired t-test). (B) Flies were starved on mineral water for $21 \mathrm{hrs}$ and then trained with an appetitive associative olfactory learning protocol (odor paired with sucrose ingestion). Short-term memory (STM) performance was measured $1 \mathrm{hr}$ after learning. The STM score of flies mutant for Trm7_34 (Mut Trm7_34 $\left.{ }^{\mathrm{e} 2001}\right)$ was not different from their genotypic controls $\left(w^{1118}\right)(n=11$ per condition; $\mathrm{p}=0.85$; two-tailed unpaired t-test). (C) Flies were starved on mineral water for $21 \mathrm{hrs}$, and their attraction to sucrose was then measured. The innate sucrose preference of flies mutant for Trm7_34 (Mut Trm7_34 ${ }^{\mathrm{e} 2001}$ ) was not different from their genotypic controls $\left(\mathrm{w}^{1118}\right)(\mathrm{n}=16$ per condition; $p=0.48$; two-tailed unpaired t-test). (D) Flies were starved on mineral water for 21 hrs, and their avoidance to the odorants used in the olfactory memory assays, 3-octanol (OCT) and 4-methylcyclohexanol $(\mathrm{MCH})$ was then measured. The innate odor avoidance of flies mutant for Trm7_34 (Mut Trm7_34 $4^{\mathrm{e} 02001}$ ) was not different from their genotypic controls $\left(\mathrm{w}^{1118}\right)(\mathrm{n}$ $=11$ per condition; OCT: $\mathrm{p}=0 . \overline{63} ; \mathrm{MCH}: \mathrm{p}=0.32$; two-tailed unpaired t-test). 
TABLES AND TABLES LEGENDS

\begin{tabular}{|c|c|c|c|}
\hline \multicolumn{4}{|c|}{ tRNA $^{\text {Phe(GAA) }}$} \\
\hline Individual & $\mathrm{Cm}_{32}$ & $\mathrm{Gm}_{34}$ & LCL code name \\
\hline $\begin{array}{c}\text { Control } \\
\text { individuals }\end{array}$ & Present & Present & $\begin{array}{l}\text { LCL16 } \\
\text { LCL18 } \\
\text { LCL24 } \\
\text { LCL54 }\end{array}$ \\
\hline $\begin{array}{l}\text { Affected individuals } \\
\text { with FTSJ1 variant }\end{array}$ & Absent & Absent & $\begin{array}{l}\text { LCL65AW } \\
\text { LCL65JW } \\
\text { LCL11 } \\
\text { LCLMM }\end{array}$ \\
\hline $\begin{array}{l}\text { Affected individual } \\
\text { with FTSJ1 variant }\end{array}$ & Present & Absent & LCL22 \\
\hline
\end{tabular}

Table 1. FTSJ1 targets tRNA $^{\text {Phe }}$ at positions 32 and 34 in humans. Control and affected FTSJ1 individuals Nm status at positions 32 and 34 of human tRNA ${ }^{\text {Phe }}$.

\begin{tabular}{|c|c|c|c|c|c|c|c|c|}
\hline \multirow{3}{*}{ tRNA target } & \multicolumn{4}{|c|}{ Human } & \multicolumn{2}{|c|}{ Drosophila } & \multicolumn{2}{|c|}{ S. cerevisiae } \\
\hline & \multicolumn{2}{|c|}{$\begin{array}{c}\text { Current } \\
\text { RiboMethSeq study }\end{array}$} & \multicolumn{2}{|c|}{ Previous MS studies } & \multicolumn{2}{|c|}{ RiboMethSeq study } & \multicolumn{2}{|c|}{ MS studies } \\
\hline & Position 32 & Position 34 & Position 32 & Position 34 & Position 32 & Position 34 & Position 32 & Position 34 \\
\hline $\operatorname{Arg}($ UCG) & $\mathrm{Cm}$ & no & $\mathrm{Cm}$ & no & no & no & n.d. & n.d. \\
\hline $\operatorname{Arg}(A C G)$ & no & no & $\mathrm{Cm}$ & no & $\mathrm{Cm}$ & no & n.d. & n.d. \\
\hline $\operatorname{Arg}(\mathrm{CCG})$ & no & no & Um & $\mathrm{Cm}$ & no & no & n.d. & n.d. \\
\hline Leu(CAG) & no & $\mathrm{Cm}$ & n.d. & $\mathrm{Cm}$ & no & no & n.d. & n.d. \\
\hline Leu(CAA) & no & no & n.d. & $\mathrm{Cm}$ & $\mathrm{Cm}$ & $\mathrm{Cm}$ & n.d. & n.d. \\
\hline Leu(UAA) & no & no & n.d. & no & no & no & $\mathrm{Cm}$ & $\mathrm{Cm}$ \\
\hline Leu(AAG) & no & no & n.d. & no & no & no & n.d. & n.d. \\
\hline Leu(UAG) & no & no & n.d. & no & no & no & n.d. & n.d. \\
\hline Phe(GAA) & no & Gm & $\mathrm{Cm}$ & Gm & no & Gm & $\mathrm{Cm}$ & Gm \\
\hline $\operatorname{Trp}(\mathrm{CCA})$ & $\mathrm{Cm}$ & $\mathrm{Cm}$ & $\mathrm{Cm}$ & $\mathrm{Cm}$ & $\mathrm{Cm}$ & $\mathrm{Cm}$ & $\mathrm{Cm}$ & $\mathrm{Cm}$ \\
\hline $\mathrm{G} \ln (\mathrm{CUG})$ & $\mathrm{Cm}$ & no & n.d. & n.d. & $\mathrm{Cm}$ & no & n.d. & n.d. \\
\hline Gln(UUG) & no & no & $\mathrm{Cm}$ & n.d. & no & no & n.d. & n.d. \\
\hline Gly(CCC) & Um & no & n.d. & no & no & no & n.d. & n.d. \\
\hline Glu(CUC) & no & no & n.d. & n.d. & $\mathrm{Cm}$ & no & n.d. & n.d. \\
\hline $\operatorname{Val}(A A C)$ & no & no & n.d. & n.d. & $\mathrm{Cm}$ & no & n.d. & n.d. \\
\hline Asn((GUU) & no & no & n.d. & n.d. & $\mathrm{Cm}$ & no & n.d. & n.d. \\
\hline Ala(AGC) & no & no & n.d. & n.d. & Um & no & n.d. & n.d. \\
\hline
\end{tabular}

Table 2. FTSJ1 targets multiple human tRNAs at positions 32 and 34 . A summary of tRNA nucleotides revealed to date, including by the current study, as targets of human FTSJ1, as well as those targeted by Drosophila Trm7 32 and Trm7_34, and yeast Trm7 in the respective organisms. For the tRNA targets are given the isotype (determined by the bound amino acid) and the isoacceptor (determined by the ACL sequence). In blue are highlighted the studies done with the site-specific RiboMethSeq and in grey, the ones done by mass spectrometry (MS) single nucleotide analysis. n.d. stands for non-determined and indicates that the tRNA was not tested or if tested the data was not analysable. no stands for non-detected Nm. Cm, Gm and Um stand for 2'-O-methylated respectively C, G and U nucleotides. 
bioRxiv preprint doi: https://doi.org/10.1101/2021.02.06.430044; this version posted May 22,2021 . The copyright holder for this preprint

(which was not certified by peer review) is the author/funder, who has granted bioRxiv a license to display the preprint in perpetuity. It is made available under aCC-BY-NC-ND 4.0 International license.

\begin{tabular}{|c|c|c|c|c|c|c|c|c|c|c|c|}
\hline$\#$ & Symbol & $\begin{array}{l}\text { baseMean } \\
\text { _mutant }\end{array}$ & $\begin{array}{l}\text { baseMean } \\
\text {-wt }\end{array}$ & $\begin{array}{l}\text { log2FoldChange } \\
\text { _Mutant_vs_WT }\end{array}$ & padj & $\#$ & Symbol & $\begin{array}{l}\text { baseMea } \\
\text { n_mutan } \\
t\end{array}$ & $\begin{array}{l}\text { baseMean } \\
\text { _wt }\end{array}$ & $\begin{array}{l}\text { log2FoldChange } \\
\text {-Mutant_vs_WT }\end{array}$ & padj \\
\hline 1 & SASH1 & 1002,73 & 7,65 & 7,33 & $2,69 \mathrm{E}-41$ & 36 & RNASE6 & 639,96 & 1645,30 & $-1,72$ & $1,43 \mathrm{E}-07$ \\
\hline 2 & FCRL4 & 515,44 & 7,09 & 6,05 & $2,08 \mathrm{E}-26$ & 37 & CD38 & 3629,12 & 297,01 & 2,52 & $1,60 \mathrm{E}-07$ \\
\hline 3 & GSTT1 & 381,66 & 1,49 & 8,82 & $1,81 \mathrm{E}-18$ & 38 & LOC728640 & 2914,46 & 2322,11 & 0,80 & $2,04 \mathrm{E}-07$ \\
\hline 4 & PPP1R21 & 5078,43 & 6380,13 & $-1,06$ & $1,92 \mathrm{E}-17$ & 39 & APBB2 & 1332,24 & 3371,16 & $-2,21$ & $2,18 \mathrm{E}-07$ \\
\hline 5 & TINAG & 522,56 & 2,62 & 7,59 & $5,23 \mathrm{E}-17$ & 40 & USMG5 & 7566,88 & 6750,46 & 0,76 & $2,45 E-07$ \\
\hline 6 & ADCY6 & 544,04 & 17,61 & 3,38 & $1,20 \mathrm{E}-16$ & 41 & FBN2 & 638,23 & 76,83 & 3,67 & $2,64 \mathrm{E}-07$ \\
\hline 7 & DSC2 & 990,21 & 134,24 & 3,01 & $9,55 \mathrm{E}-15$ & 42 & HTR7 & 2,11 & 273,06 & $-21,67$ & $3,12 \mathrm{E}-07$ \\
\hline 8 & IL17RB & 3188,28 & 616,47 & 3,45 & $1,22 \mathrm{E}-14$ & 43 & ALOX5 & 1890,29 & 5091,55 & $-2,91$ & $3,96 \mathrm{E}-07$ \\
\hline 9 & ABCA12 & 1267,89 & 3695,42 & $-3,75$ & $1,49 \mathrm{E}-14$ & 44 & DDX60L & 962,23 & 110,32 & 2,42 & $5,75 \mathrm{E}-07$ \\
\hline 10 & JAZF1 & 333,25 & 17,53 & 5,14 & $1,99 \mathrm{E}-14$ & 45 & B3GALNT1 & 617,28 & 26,67 & 4,51 & $8,73 \mathrm{E}-07$ \\
\hline 11 & TNRC6C & 1612,67 & 274,90 & 2,90 & $3,30 \mathrm{E}-14$ & 46 & cox7B & 12243,87 & 9892,47 & 0,64 & $1,05 \mathrm{E}-06$ \\
\hline 12 & SYNE1 & 4579,60 & 5860,78 & $-0,97$ & $2,35 \mathrm{E}-13$ & 47 & CBLB & 3203,88 & 5817,18 & $-1,72$ & $1,33 \mathrm{E}-06$ \\
\hline 13 & СРXM1 & 2071,71 & 6,69 & 8,34 & $2,34 \mathrm{E}-12$ & 48 & PAPLN & 1212,67 & 3785,94 & $-1,77$ & $1,35 \mathrm{E}-06$ \\
\hline 14 & FNIP2 & 787,53 & 60,32 & 2,80 & $8,93 \mathrm{E}-12$ & 49 & ANKRD26P3 & 561,85 & 2,58 & 8,71 & $1,79 \mathrm{E}-06$ \\
\hline 15 & $\mathrm{CDH} 2$ & 1169,70 & 45,93 & 5,50 & $1,06 \mathrm{E}-10$ & 50 & ACVR2B & 355,06 & 771,16 & $-1,78$ & $1,88 \mathrm{E}-06$ \\
\hline 16 & TBX15 & 2674,86 & 22,11 & 5,58 & $1,52 \mathrm{E}-10$ & 51 & RBPMS & 341,58 & 0,52 & 8,65 & $2,01 \mathrm{E}-06$ \\
\hline 17 & C14orf105 & 2783,34 & 168,09 & 3,35 & $4,51 \mathrm{E}-10$ & 52 & PSMD7 & 34420,17 & 28659,74 & 0,64 & $2,07 \mathrm{E}-06$ \\
\hline 18 & AMPD3 & 1793,58 & 4186,29 & $-2,29$ & $5,50 \mathrm{E}-10$ & 53 & MPHOSPH8 & 33819,66 & 28333,28 & 0,63 & $2,38 \mathrm{E}-06$ \\
\hline 19 & GAS2 & 2013,39 & 25,82 & 5,45 & $7,09 \mathrm{E}-10$ & 54 & CTSW & 110,71 & 8,47 & 5,36 & $2,71 \mathrm{E}-06$ \\
\hline 20 & EVC & 293,08 & 3187,02 & $-6,61$ & $7,09 \mathrm{E}-10$ & 55 & MYO9B & 10534,78 & 14242,52 & $-0,53$ & $2,84 \mathrm{E}-06$ \\
\hline 21 & TNFAIP2 & 1331,48 & 3608,85 & $-1,82$ & $1,15 \mathrm{E}-09$ & 56 & IQGAP2 & 6537,41 & 9197,51 & $-1,20$ & $3,22 \mathrm{E}-06$ \\
\hline 22 & TSPYL5 & 829,00 & 72,33 & 3,10 & 1,19E-09 & 57 & AMOTL1 & 2535,84 & 68,85 & 3,67 & $3,94 \mathrm{E}-06$ \\
\hline 23 & HERC5 & 11068,07 & 2191,72 & 1,45 & $1,98 \mathrm{E}-09$ & 58 & MANEAL & 354,94 & 982,06 & $-1,69$ & $4,72 \mathrm{E}-06$ \\
\hline 24 & UBE2QL1 & 205,44 & 53,77 & 3,16 & $2,23 \mathrm{E}-09$ & 59 & SPATS2L & 7329,68 & 2990,72 & 0,97 & 4,97E-06 \\
\hline 25 & ARHGAP6 & 3915,43 & 352,19 & 3,53 & $2,73 \mathrm{E}-09$ & 60 & VEGFB & 6472,65 & 5415,88 & 0,90 & $5,21 \mathrm{E}-06$ \\
\hline 26 & SLAIN1 & 6757,48 & 3157,85 & 1,24 & $2,73 E-09$ & 61 & ATP1B1 & 7552,46 & 859,00 & 2,47 & $5,25 E-06$ \\
\hline 27 & CERS6 & 5027,25 & 5425,85 & $-1,13$ & $3,74 \mathrm{E}-09$ & 62 & SIX3 & 800,36 & 1203,65 & $-6,36$ & $5,25 \mathrm{E}-06$ \\
\hline 28 & ATP8B1 & 296,62 & 13,02 & 3,73 & 5,99E-09 & 63 & LOC285972 & 1639,86 & 2658,04 & $-1,16$ & $7,04 \mathrm{E}-06$ \\
\hline 29 & GRIA3 & 43,74 & 504,25 & $-3,95$ & $7,66 \mathrm{E}-09$ & 64 & MY018A & 8284,31 & 9316,46 & $-0,69$ & $8,77 \mathrm{E}-06$ \\
\hline 30 & MARCH8 & 1078,97 & 1225,73 & $-1,64$ & $7,68 \mathrm{E}-09$ & 65 & L1TD1 & 67,03 & 1,01 & 8,23 & $8,90 \mathrm{E}-06$ \\
\hline 31 & DUSP4 & 17734,90 & 5898,88 & 1,94 & $1,58 \mathrm{E}-08$ & 66 & RRP7B & 3521,07 & 2614,81 & 0,94 & $9,80 \mathrm{E}-06$ \\
\hline 32 & EPB41L5 & 1929,07 & 494,79 & 1,93 & $1,70 \mathrm{E}-08$ & 67 & SPARC & 4705,62 & 16484,18 & $-1,60$ & 1,51E-05 \\
\hline 33 & ZNF711 & 1265,24 & 3592,15 & $-3,34$ & $1,05 E-07$ & 68 & ESF1 & 32558,55 & 26226,19 & 0,69 & $1,60 \mathrm{E}-05$ \\
\hline 34 & RGS2 & 1264,73 & 83,46 & 3,85 & $1,26 \mathrm{E}-07$ & 69 & FUT8 & 10906,46 & 16945,75 & $-0,94$ & $1,64 \mathrm{E}-05$ \\
\hline 35 & TP53BP2 & 2231,99 & 622,32 & 2,13 & $1,41 \mathrm{E}-07$ & 70 & MIR363 & 109,28 & 0,00 & 8,71 & $1,71 \mathrm{E}-05$ \\
\hline
\end{tabular}

Table 3. FTSJ1 loss of function leads to mRNAs deregulation in NSXLID affected individuals LCLs. A list of the 70 most significantly deregulated mRNAs in FTSJ1 LCLs mutants versus controls. 


\begin{tabular}{|c|c|c|c|}
\hline miRNA & Brain related & Brain cancer related & Cancer related \\
\hline hsa-miR-20b-5p & - & - & (Khuu et al. 2016) \\
\hline hsa-miR-222-3p & $\begin{array}{l}\text { (Lau et al. 2013) } \\
\text { (Kretschmann et al. 2015) } \\
\text { (Kan et al. 2012) } \\
\text { (Risbud and Porter 2013) }\end{array}$ & $\begin{array}{l}\text { (Gillies and Lorimer 2007) } \\
\text { (C.-Z. Zhang et al. 2010) }\end{array}$ & - \\
\hline hsa-miR-548ax & - & $\begin{array}{l}\text { neuroblastoma for other } \\
\text { miR-548 family members }\end{array}$ & $\begin{array}{l}\text { (Watahiki et al. 2011) (also } \\
\text { others cancers for other } \\
\text { miR-548 family members) }\end{array}$ \\
\hline hsa-miR-125b-2-3p & yes & yes & yes \\
\hline hsa-miR-221-3p & $\begin{array}{l}\text { (Kretschmann et al. 2015) } \\
\text { (Kan et al. 2012) } \\
\text { (Risbud and Porter 2013) } \\
\text { (Ding et al. 2016) } \\
\text { (Ma et al. 2016) } \\
\text { (Roser et al. 2018) }\end{array}$ & (see miR-222-3p) & (Fornari et al. 2008) \\
\hline hsa-miR-335-3p & yes & yes & yes \\
\hline hsa-miR-181b-2-3p & (see miR(181a-5p) & (see miR(181a-5p) & (see miR(181a-5p) \\
\hline hsa-miR-99a-5p & yes & yes & yes \\
\hline hsa-miR-10a-5p & $\begin{array}{l}\text { (Gui et al. 2015) } \\
\text { (Roser et al. 2018) }\end{array}$ & $\begin{array}{l}\text { (Tehler, Høyland-Kroghsbo, } \\
\text { and Lund 2011) } \\
\text { (Lund 2010) }\end{array}$ & $\begin{array}{l}\text { (Tehler, Høyland-Kroghsbo, } \\
\text { and Lund 2011) } \\
\text { (Lund 2010) }\end{array}$ \\
\hline hsa-miR-181b-3p & (see miR(181a-5p) & $($ see $\operatorname{miR}(181 a-5 p)$ & (see miR(181a-5p) \\
\hline hsa-miR-106a-5p & yes & yes & yes \\
\hline hsa-miR-181a-2-3p & (see miR(181a-5p) & $($ see $\operatorname{miR}(181 a-5 p)$ & $($ see miR(181a-5p) \\
\hline hsa-miR-146a-5p & yes & yes & yes \\
\hline hsa-miR-4482-3p & - & - & - \\
\hline hsa-miR-125b-5p & yes & yes & yes \\
\hline hsa-miR-450b-5p & - & - & yes \\
\hline hsa-miR-424-3p & yes & - & yes \\
\hline hsa-miR-363-3p & $\begin{array}{l}\text { (Lau et al. 2013) } \\
\text { (Kiyosawa et al. 2019) }\end{array}$ & $\begin{array}{l}\text { (Conti et al. 2016) } \\
\text { (Qiao et al. 2013) }\end{array}$ & $\begin{array}{l}\text { (Jiang et al. 2018) } \\
\text { (Ye et al. 2017) } \\
\text { (Hu et al. 2016) } \\
\text { (Wang et al. 2016) } \\
\text { (Karatas et al. 2016) } \\
\text { (Chapman et al. 2015) } \\
\text { (P.-F. Zhang et al. 2016) } \\
\text { (Khuu et al. 2016) }\end{array}$ \\
\hline hsa-let-7c-5p & - & - & - \\
\hline hsa-miR-450a-5p & yes & - & yes \\
\hline hsa-miR-18b-5p & - & - & - \\
\hline hsa-miR-550a-3p & - & - & yes \\
\hline hsa-miR-181a-5p & $\begin{array}{l}\text { (S.-F. Zhang et al. 2017) } \\
\text { (Ding et al. 2016) } \\
\text { (Roser et al. 2018) }\end{array}$ & (Shi et al. 2008) & $\begin{array}{l}\text { (Yang et al. 2017) } \\
\text { (Li et al. 2015) }\end{array}$ \\
\hline hsa-miR-550b-2-5p & - & - & yes \\
\hline hsa-miR-181a-3p & (see miR(181a-5p) & $($ see miR(181a-5p) & (see miR(181a-5p) \\
\hline hsa-miR-181b-5p & (see miR(181a-5p) & $($ see $\operatorname{miR}(181 a-5 p)$ & (see miR(181a-5p) \\
\hline hsa-miR-183-5p & yes & yes & yes \\
\hline hsa-miR-99a-3p & yes & yes & yes \\
\hline hsa-miR-135a-5p & yes & yes & yes \\
\hline
\end{tabular}


bioRxiv preprint doi: https://doi.org/10.1101/2021.02.06.430044; this version posted May 22, 2021. The copyright holder for this preprint (which was not certified by peer review) is the author/funder, who has granted bioRxiv a license to display the preprint in perpetuity. It is made available under aCC-BY-NC-ND 4.0 International license.

\begin{tabular}{|l|l|l|l|}
\hline hsa-miR-146b-5p & yes & yes & yes \\
\hline hsa-miR-542-5p & - & yes & yes \\
\hline hsa-miR-944 & yes & - & yes \\
\hline hsa-miR-625-5p & - & - & - \\
\hline hsa-miR-625-3p & - & - & - \\
\hline hsa-miR-4772-5p & - & - & yes \\
\hline hsa-miR-182-5p & yes & yes & yes \\
\hline Total \# & $\mathbf{2 4}$ & & \\
\hline
\end{tabular}

Table 4. Bibliographic search on miRNA deregulated in FTSJ1 loss-of-function LCL mutant cell line. The list shows for each miRNA if any link was found to brain development or brain-related diseases, also cancer and specifically to brain-cancers. The references are given for most of the miRNAs. The color code of the miRNA names indicates if they were found to be up- (red) or down-regulates (blue) in FTSJ1 mutant LCLs derived from NSXLID affected individuals compared to control LCLs derived from healthy individuals. 
bioRxiv preprint doi: https://doi.org/10.1101/2021.02.06.430044; this version posted May 22, 2021. The copyright holder for this preprint (which was not certified by peer review) is the author/funder, who has granted bioRxiv a license to display the preprint in perpetuity. It is made available under aCC-BY-NC-ND 4.0 International license.

\section{Figure 1}
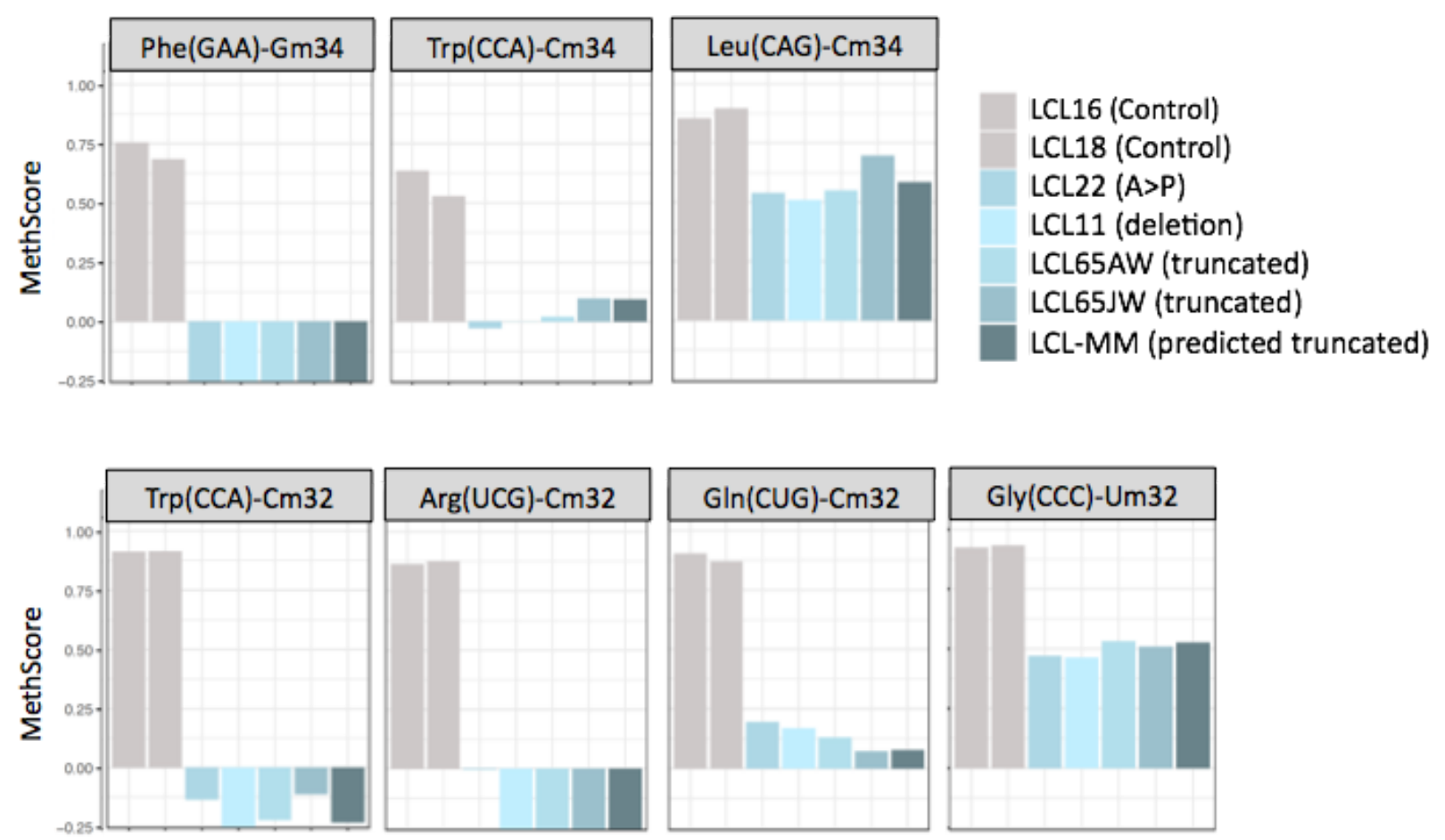
bioRxiv preprint doi: https://doi.org/10.1101/2021.02.06.430044; this version posted May 22, 2021. The copyright holder for this preprint (which was not certified by peer review) is the author/funder, who has granted bioRxiv a license to display the preprint in perpetuity. It is made available under aCC-BY-NC-ND 4.0 International license.

\section{Figure 2}

\section{A}

\section{GO Biological Process}

Brain morphogenesis (GO:0048854) Mitochondrial ATP synthesis coupled electron transport (GO:0042775) ATP synthesis coupled electron transport (GO:0042773) Oxidative phosphorylation (GO:0006119) NIK/NF-kappaB signaling (GO:0038061) Mitochondrial translational elongation (GO:0070125) Mitochondrial translational termination (GO:0070126) Translational termination (GO:0006415) Translational elongation (GO:0006414) Respiratory electron transport chain (GO:0022904) Establishment of cell polarity (GO:0030010) Establishment or maintenance of cell polarity (GO:0007163)

Cellular protein complex disassembly (GO:0043624) Regulation of morphogenesis of an epithelium (GO:1905330)

T cell receptor signaling pathway (GO:0050852) ATP metabolic process (GO:0046034) Actin cytoskeleton organization (GO:0030036)

Actin filament-based process (GO:0030029) Positive regulation of hydrolase activity (GO:0051345) Negative regulation of cell communication (GO:0010648)

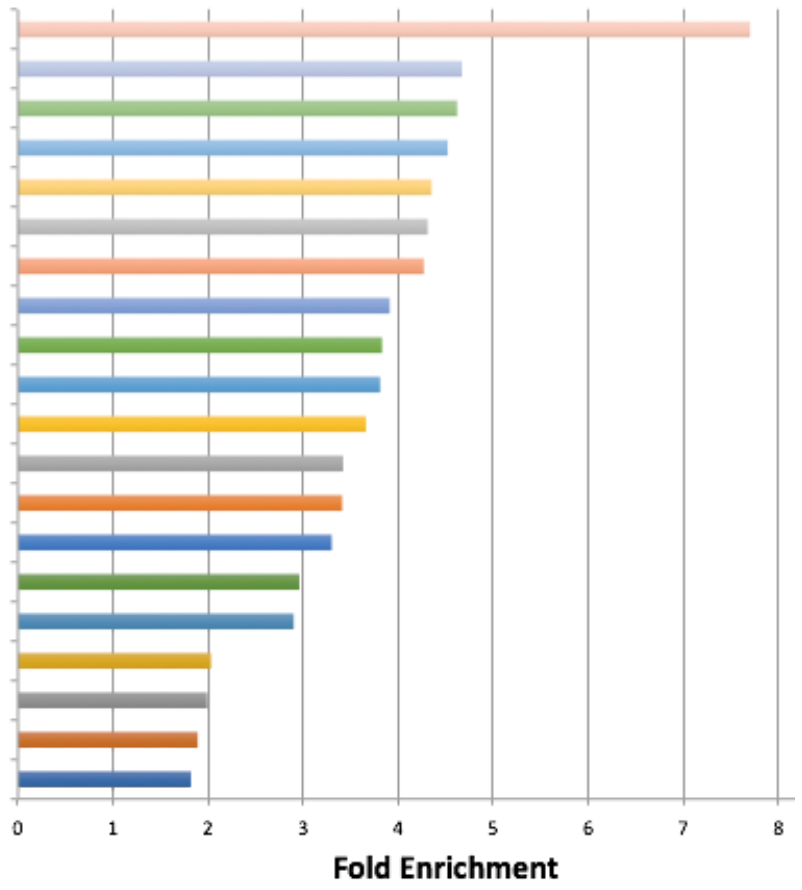

B
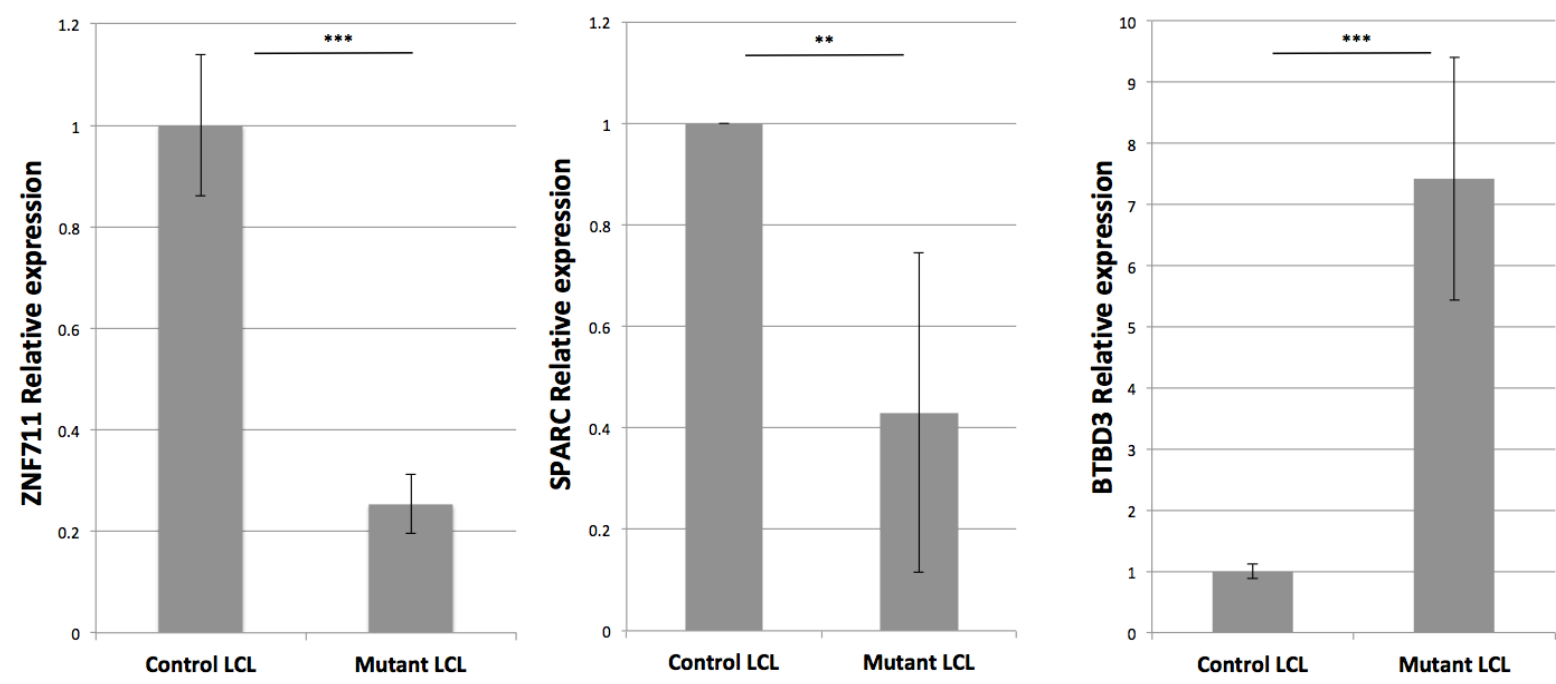
bioRxiv preprint doi: https://doi.org/10.1101/2021.02.06.430044; this version posted May 22, 2021. The copyright holder for this preprint (which was not certified by peer review) is the author/funder, who has granted bioRxiv a license to display the preprint in perpetuity. It is Figure 3 made available under aCC-BY-NC-ND 4.0 International license.

A

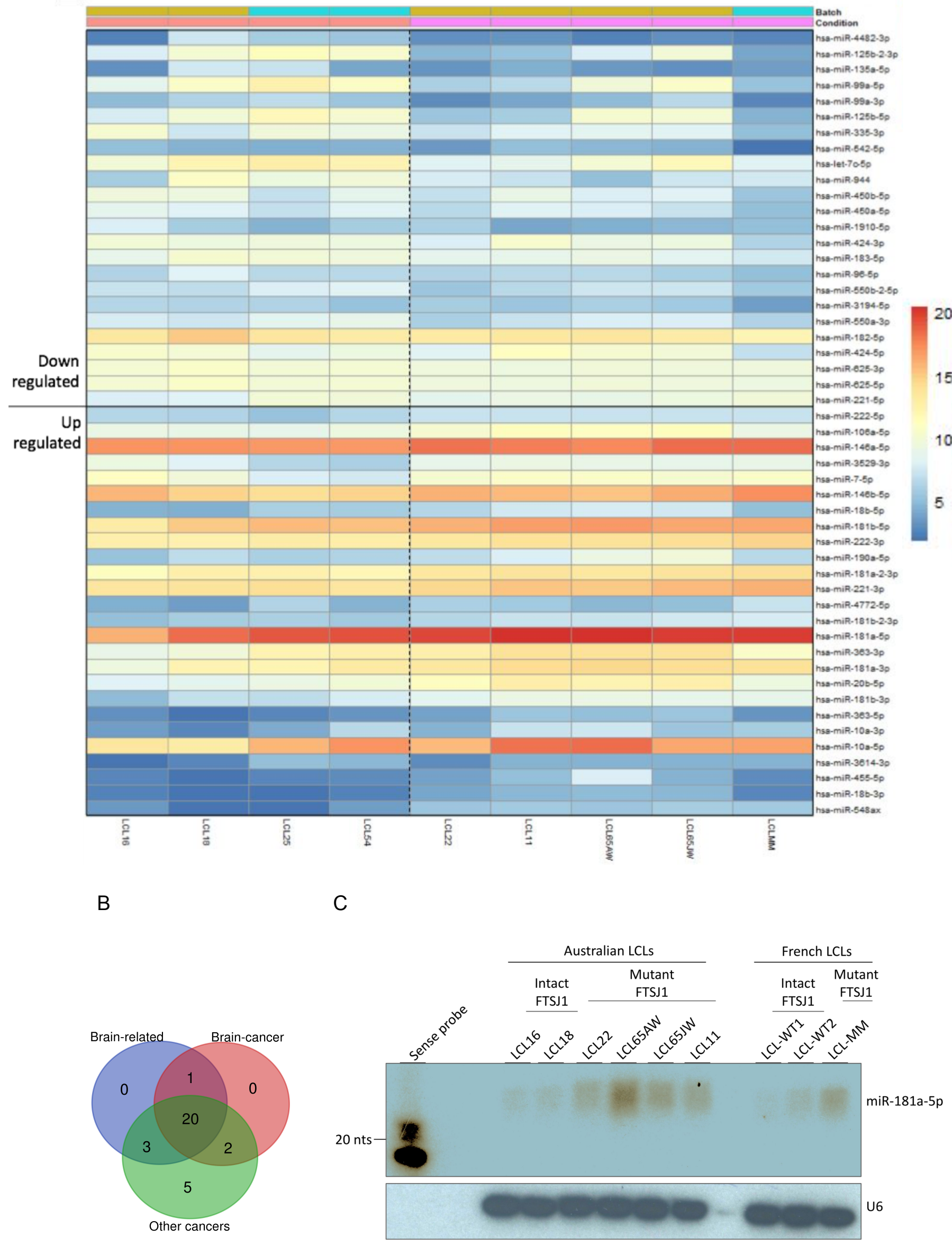


bioRxiv preprint doi: https://doi.org/10.1101/2021.02.06.430044; this version posted May 22, 2021. The copyright holder for this preprint

(which was not certified by peer review) is the author/funder, who has granted bioRxiv a license to display the preprint in perpetuity. It is made available under aCC-BY-NC-ND 4.0 International license.

Figure 4

A

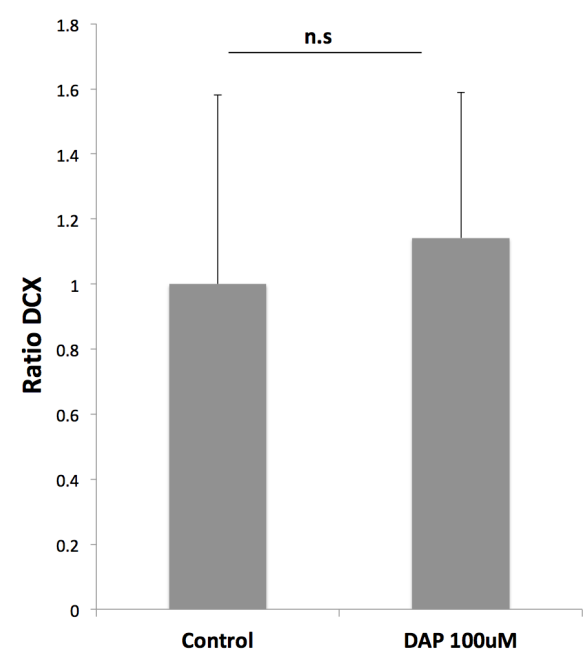

C

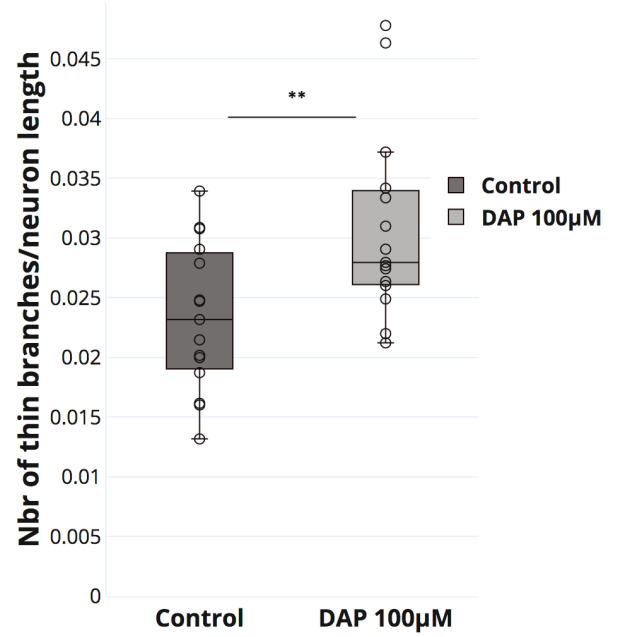

B
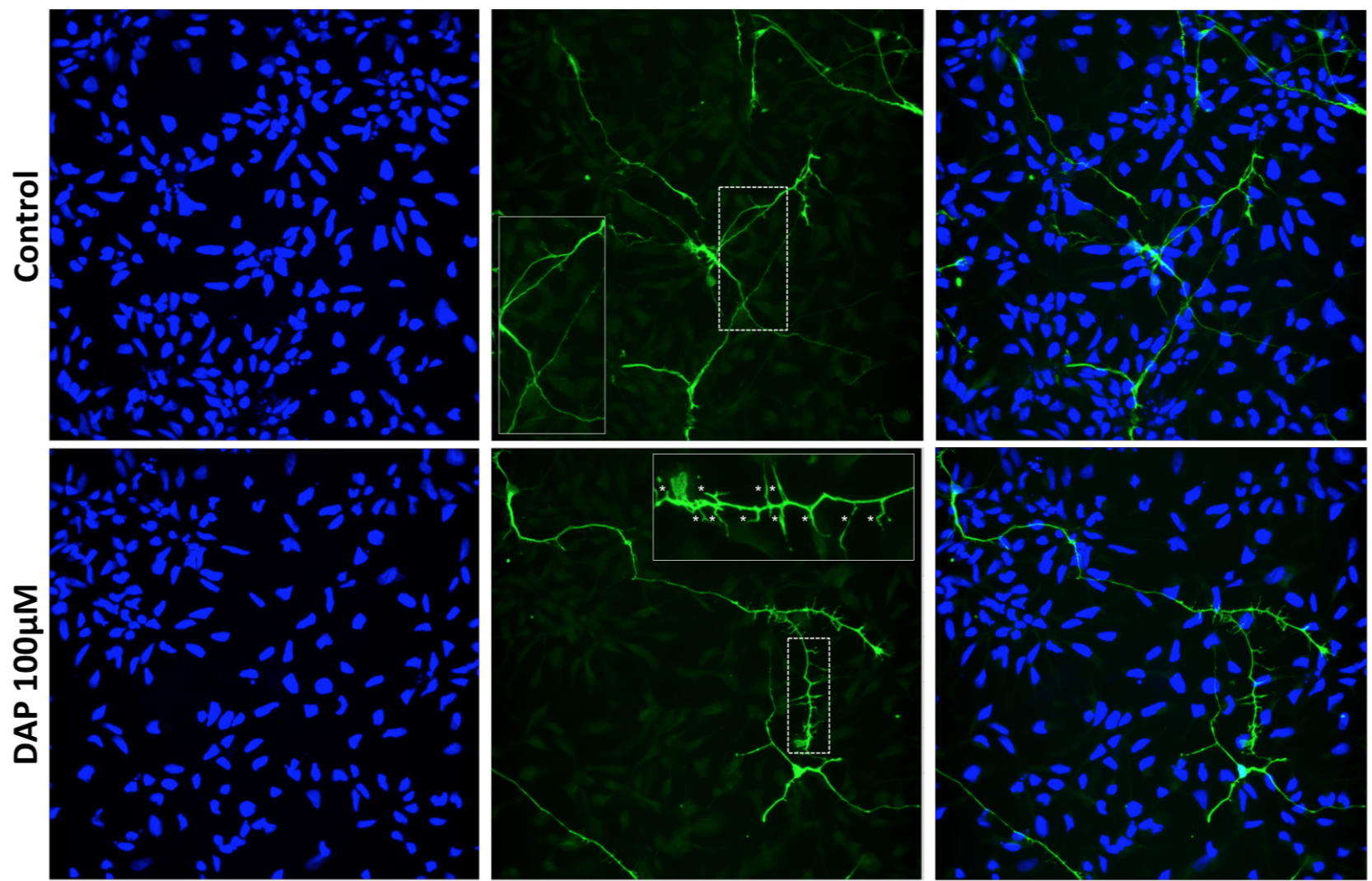

DAPI

DCX

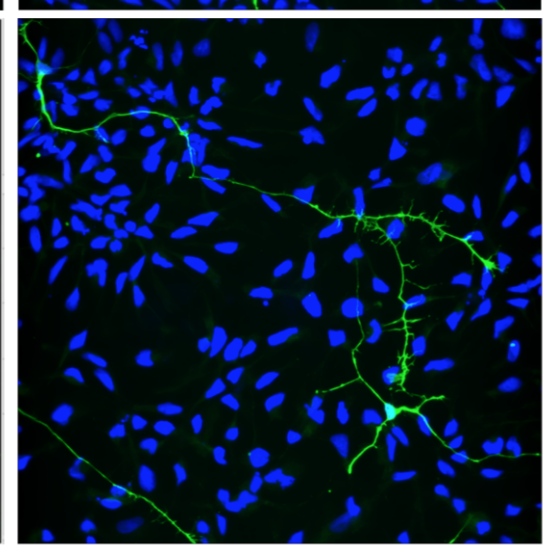

Merge 
bioRxiv preprint doi: https://doi.org/10.1101/2021.02.06.430044; this version posted May 22, 2021. The copyright holder for this preprint

(which was not certified by peer review) is the author/funder, who has granted bioRxiv a license to display the preprint in perpetuity. It is made available under aCC-BY-NC-ND 4.0 International license.

Figure 5
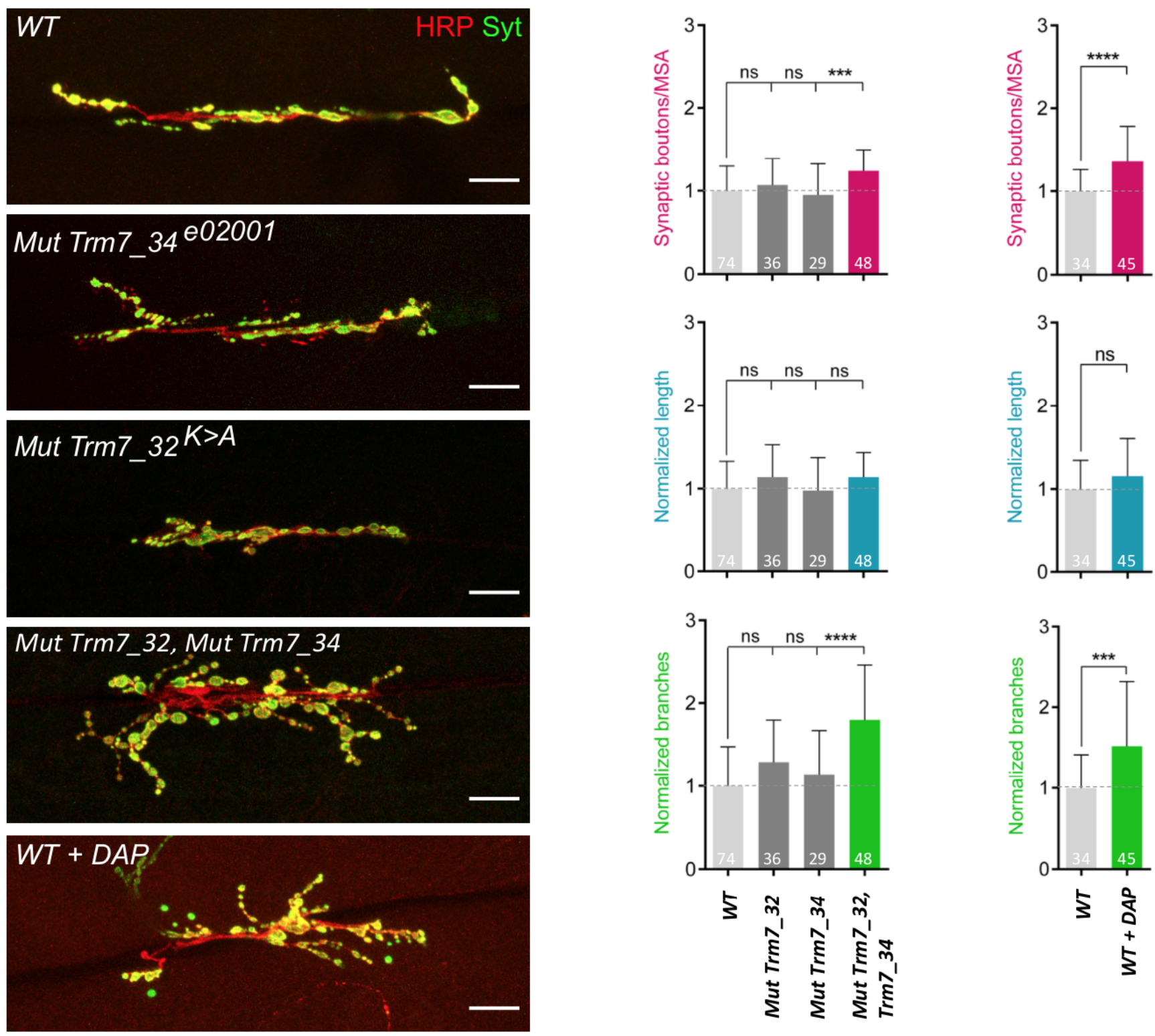
bioRxiv preprint doi: https://doi.org/10.1101/2021.02.06.430044; this version posted May 22, 2021. The copyright holder for this preprint (which was not certified by peer review) is the author/funder, who has granted bioRxiv a license to display the preprint in perpetuity. It is made available under aCC-BY-NC-ND 4.0 International license.

\section{Figure 6}

A

Appetitive LTM

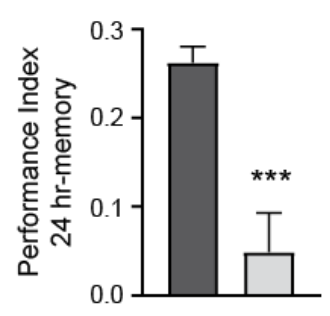

B

Appetitive STM

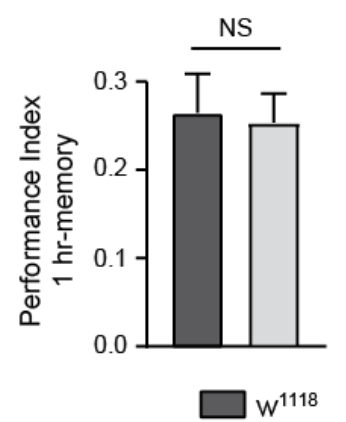

C

Innate sucrose attraction

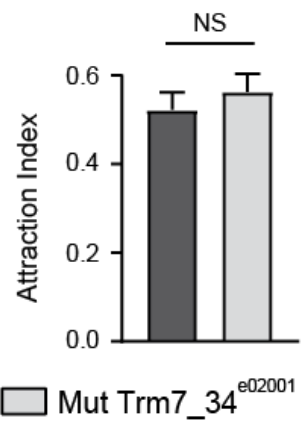

D

Innate odor

avoidance

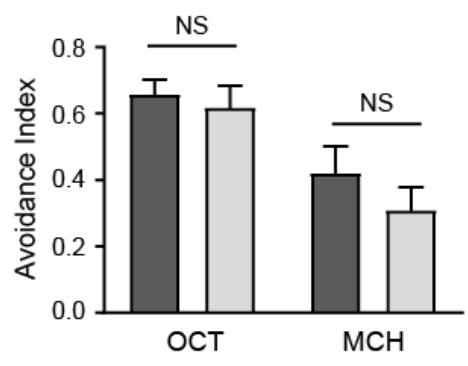

